\title{
La Campaña Carlista (1872-1876) en Le Monde Illustré: Los dibujos de Daniel Vierge
}

\author{
M. ${ }^{a}$ Dolores Bastida de la Calle *
}

Era febrero de 1870 , vispera de revolución en París, cuando aparecia en Le Monde Illustré una primera estampa con la firma "Vierge", un conflicto de carlistas y liberales en Murcia. Su autor, llegado en el 69 a Paris con 18 años, inicia asi una carrera que le marcará como "el mejor ilustrador en blanco y negro del período" '. Fueron los sketches sobre la Comuna los que le llevaron el primer reconocimiento de público y director del semanario francés. Ofrecia Vierge una manera nueva en la técnica de historiar la realidad. "Como Goya durante la guerra de la Independencia y Fortuny en la campaña de Marruecos, fue testigo presencial de aquellos sucesos y sus bocetos tenían la señal de autenticidad "?

Su arte, sin embargo, no se agotaba en el dibujo "d'après nature"; en breve tiempo Vierge pasa a dibujante de estudio en la Redacción, un puesto de particular relevancia en los semanarios ilustrados franceses, en el que imaginación y factura consolidaron su nombre. El 18 de mayo del 72 publica Le Monde Illustré una carta de su corresponsal gráfico en la incipiente guerra carlista, Vicente Urrabieta, dibujante de sólida reputación iniciada en los años cincuenta, quien muestra una admiración ilimitada por el acabado que de sus croquis, publicados dos semanas

* Departamento de historia del arte (UNED). Agradezco a la Biblioteca Nacional las ilustraciones.

'Du Gue Trapier, Elizabeth, A Sketch Book by the Young Vierge. New York, The Hispanic Society of America, 1936.

2 Du gue Trapier, Elizabeth, Daniel Urrabieta Vierge in the collection of the Hispanic Society of America. New York, The Hispanic Society of America, 1936, pág. Vill. 
antes, habia realizado "M. Vierge»; la carta (Fig. 1) no menciona que el ilustrador elogiado es su hijo Daniel, lo que posiblemente ignorase el público: en su prolongada carrera en París, el artista usó exclusivamente el apellido de su madre, Juana Vierge, hija de un soldado de Napoléon establecido en Madrid tras la retirada de 1812. Su entrada en 1874, en la crónica del libro ilustrado francés, situó a Daniel finalmente entre los maestros de la gran tradición francesa en ilustración: Daumier, Gavarni, Doré, Johannot...

Aunque la extensa obra de Daniel Vierge ha sido muy estudiada ${ }^{3}$, no se han analizado las numerosas ilustraciones, que sobre el conflicto carlista, publicó Le Monde Illustré. Las ilustraciones, basadas en croquis tomados por corresponsales en uno y otro bando, abarcan el periodo de

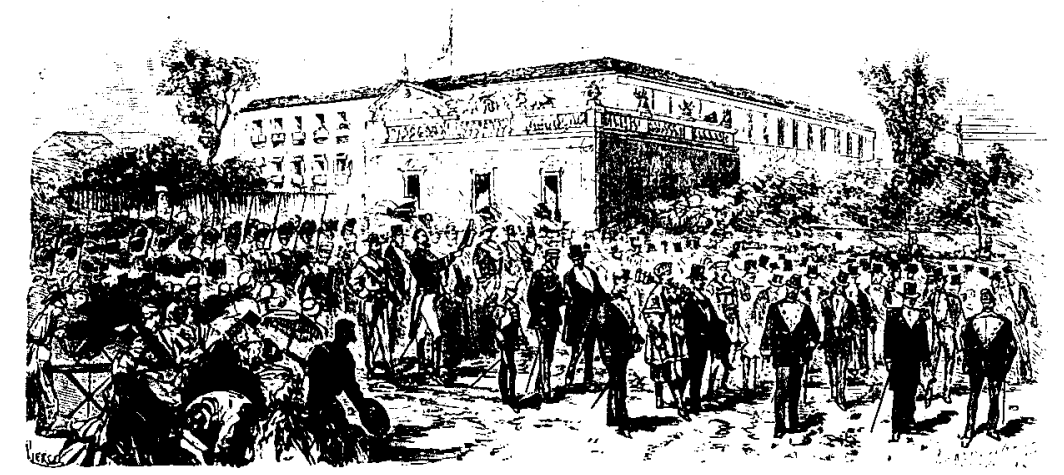

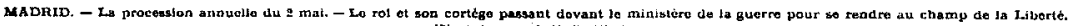

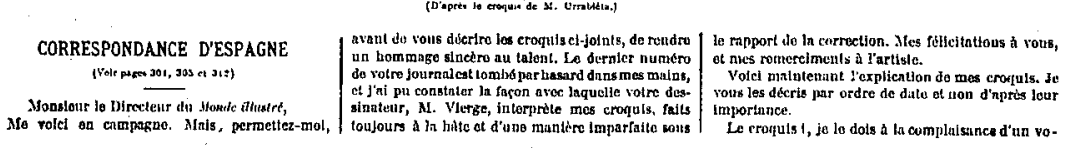

Fig. 1. Le Monde Illustré, mayo 18, 1872.

${ }^{3}$ Marx, Roger, “Daniel Vierge”, L'Image, Paris, 1897, págs. 97-103; Marthold, Jules DE, Daniel Vierge. Sa vie, son oeuvre. París, H. Floury, Libraire Editeur, 1906; PEREZ, Dionisio, Daniel Vierge, el renovador y el príncipe de la ilustración moderna. Madrid, Compañia Ibero-Americana de Publicaciones, 1929; GUSMAN, Pierre, La gravure sur bois en France au XIX siècle. París, Albert Morancé, 1929, págs. 122-125; FilguelRa Valverde, José, El viaje a Galicia de Urrabieta Vierge. Santiago de Compostela, Gráfico Galaico, 1969; RaY, Gordon N., The Art of the French Illustrated Book, 1700 to 1914. New York, Dover, 1985, págs. 390-396. 
4 de mayo de 1872 a 11 de marzo de 1876; cuatro fueron reproducidas por procedimientos fotomecánicos y cincuenta xilográficamente, tres de ellas a partir de fotografía. Los temas de los grabados recorren toda la gama de gustos de Vierge: la animación en las fiestas, el esplendor en las grandes ocasiones, el movimiento en las batallas. Todos mantienen el sello de elegancia y movimiento característico del dibujo de Vierge: soltura y delicadeza japonesa en el trazo ${ }^{4}$, vigor y vida en escena llenas de acción.

Como señala Baudelaire «la gran cualidad del dibujo de los artistas supremos es la verdad del movimiento" ${ }^{5}$ y esta era la pasión de Vierge. En 1873 el artista está ocupado en ilustrar la novela de Víctor Hugo L'année terrible, aparecida al año siguiente, y sólo publica cuatro ilustraciones sobre el conflicto; en el 75 sale a la luz L'Homme que rit y en el 76 Les travailleurs de la mer, en la que colaboran también Chifflart y el mismo Victor Hugo: Vierge se encarga de las escenas de acción de la novela ${ }^{6}$. La relación con el escritor fue sólida; el padre de Juana habia sido ordenanza del general Hugo durante la ocupación napoleónica de la Peninsula.

\section{LA IMAGEN DE ESPAÑA: LO NUEVO Y LO VIEJO}

Dos aspectos sobresalen en los grabados de Le Monde Illustré sobre el conflicto carlista: la imagen que de la guerra nos da Vierge, y su especial factura dibujística. Un examen de la temática de las estampas nos muestra, por una parte, una iconografía de guerra moderna en una España moderna: la sociedad civil que interviene en la vida política del país, los medios de comunicación, el maquinismo industrial creciente.

El grabado "Madrid- Ouverture des Cortès" (fig. 2) del 11 de mayo de 1872 ilustra la periferia de la guerra y es un retrato de gran valor para entender la España de aquel tiempo, la de la lucha de viejos y nuevos,

4 "Vierge pudo haberse interesado desde una fechá temprana por el arte japonés, especialmente el de Hokusai, del que París era un antiguo entusiasta y sobre el que las Exposiciones Universales habian hecho mucho por acrecentar el interés". DU GUE TRAPIER, Elizabeth, Daniel Urrabieta..., pág. XII).

5 Baudelaire, Charles, Curiosidades estéticas. Madrid, Ediciones Júcar, 1988, pág. 58.

6 Ray, Gordon N., obra citada, pág. 355. 


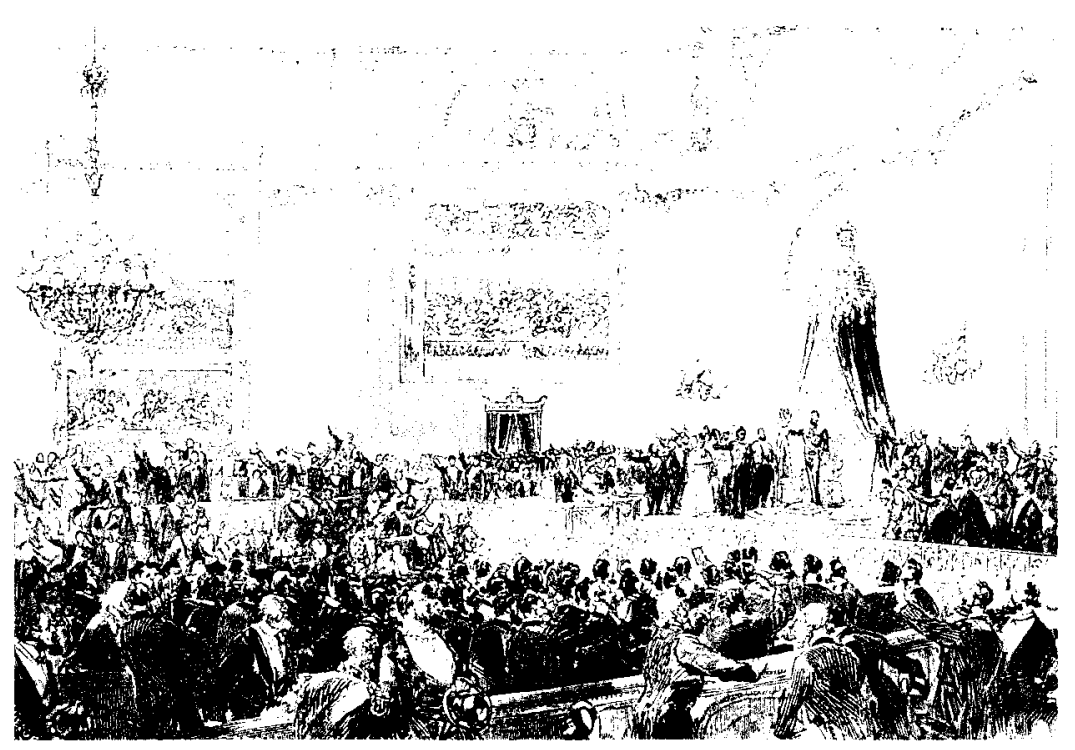

Fig. 2. Le Monde Illustré, mayo 11, 1872.

captada por Vierge con un realismo extraordinario. En el momento en que el Rey Amadeo recomendaba la unión de todos los españoles para evitar la guerra civil, la mayor parte de la cámara se puso en pie gritando «imuerte a los carlistas!».

Trenes y prensa juegan también a enfatizar la modernidad iconográfica de la narración plástica del conflicto, en el que "los hijos del Pirineo $y$ del Ebro se revuelven contra el espíritu de la meseta castellana" ?. "Une bande de carlistes détruisant la voie ferrée près d'Irurzun (Navarre); Les redacteurs carlistes de la Esperanza et de la Epoca, conduits à la prison de San Francisco, à Madrid; Le maréchal Serrano et son étatmajor quittant Madrid par la gare du Midi pour se rendre en Navarre", 11 de mayo de 1872 (Fig. 3). El asalto a trenes por parte de los carlistas dificultaba el desarrollo de la guerra a los liberales, al impedir el traslado del personal del ejército, evidencia de un aire nuevo en la concepción de la guerra. Por otra parte, el ferrocarril permitía a las revistas mostrar

\footnotetext{
Unamuno, Miguel de, Paz en la guerra. Barcelona, Plaza y Janés, 1985, pág. 104.
} 


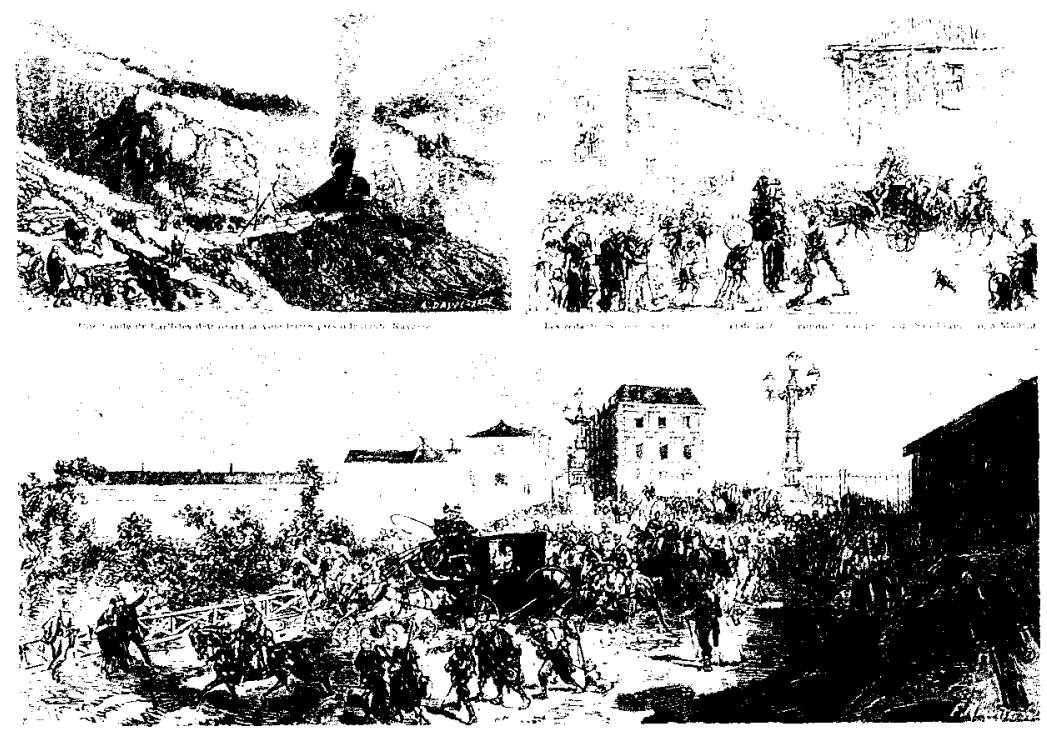

Fig. 3. Le Monde Illustré, mayo 11, 1872.

escenas de acuciante actualidad bélica, con la aceleración de la noticia del lugar de los hechos a la Redacción, y de allí al lector. Como se ha dicho, "las guerras del siglo XIX fueron de hecho, las guerras del ferrocarril» ${ }^{8}$. También la prensa llevó a cabo en este conflicto un gran despliegue propagandístico, en especial los periódicos carlistas. El segundo grabado del 11 de Mayo muestra el momento en que los redactores de La Época (1849-1936) y La Esperanza (1844-1873), que formaban parte de la Junta Católica Monárquica, son conducidos a la prisión de San Francisco el Grande, cumpliendo un auto judicial de 26 de abril por el que el Gobierno mandaba encarcelar a los miembros de la Junta.

$Y$ frente a testimonios gráficos de modernidad, la imagen de una guerra desfasada, de una realidad que parecia inbuida por la lectura exaltada "de Chateaubriand y de los demás divagadores del catolicismo romántico" ${ }^{9}$, con la figura del cura combatiendo al frente de las partidas, tropeles de aldeanos armados muchos de ellos con palos, que bajaban

8 KeEgan, John, and DaraAcott, Joseph, The Nature of War. New York, Holt, Rinehart and Winston, 1981, pág. 99.

9 Unamuno, Miguel de, obra citada, pág. 51. 
de los montes circundantes a saquear las villas, reflejo trasnochado del héroe romántico y del entusiasmo de un pueblo ("Sortie d'une bande carliste de Valdivia; La bande de Ramón Odesa, surnonmé el Cordonero, pillant le village de Tarazona", 4 de mayo de 1872) (Fig. 4). La descripción que hace Vierge del saqueo y requisa de armas en Tarazona, donde entró la banda de Odesa cerrada la noche, sugiere un mundo fantástico interpretado mediante contrastes de luces y sombras, que nos llevaría a Gustavo Doré, pero que en aquél se hace más natural, más humano.

El asalto a pueblos pequeños es una imagen recurrente de la guerra de guerrillas practicada por los carlistas, y la figura del cura beligerante se repite una y otra vez: "L'attaque du village de Lumbier à quatre lieues de Pampelune, par la bande de Peralta; La bataille d'Oroquieta" (Fig. 5), 18 de mayo de 1872. Es muy probable que al lector extranjero, la contienda le pareciese básicamente una (la última) guerra de religión europea. Muchos jefes de partidas carlistas eran sacerdotes: Oyarzun cita a Santa Cruz, cura de Hernialde, a J. A. Macazaya, cura de Orio (que aparece en la "Sonata de Invierno" de Valle Inclán); a Cruz Ochoa, quien luego sería canónigo de Toledo; al presbítero vizcaíno Goirena; a M. Miret, ex seminarista (como Cabrera); al cura Flix. En el comentario a la batalla de Oroquieta, con el que el padre de Vierge, testigo presencial, acompaña su croquis. nos cuenta como en el asalto al pueblo de Oroquieta, "un pauvre prêtre, à la tête des carlistes, a étè tué là à coups de baïonnette. Je crois le voir encore!...". La escena revela el nerviosismo, movimiento y vivacidad del dibujo de Vierge, muy miniaturista, capaz de crear la sensación de multitud en un pequeño espacio, reduciendo a rasgos esquemáticos las figuras de los últimos planos. Estamos ante ese impresionismo lineal que se plasma «a través de unas formas muy espontáneas e ingenuas, que materializan la sensación del movimiento captado en un instante determinado" ${ }^{\circ}$. En la acción de Oroquieta, el 4 de mayo de 1872, una facción de 5.000 hombres mandada por el propio Don Carlos fue batida por las tropas del general Moriones y sufrió cerca de un millar de bajas. El mismo 18 de mayo La llustración Española y Americana publicó un dibujo de Vicente Urrabieta sobre croquis del oficial A.N. (los artistas militares solian firmar con iniciales). El contraste entre ambas ilustraciones es patente ("Acción de Oroquieta en la tarde del 4 de mayo", 18 de mayo de 1872) (Fig. 6).

1 Garcia Melero, José E., "Las artes plásticas", en Historia General de España y América, Tomo XVI-1. Madrid, Rialp, 1982, pág. 188. 

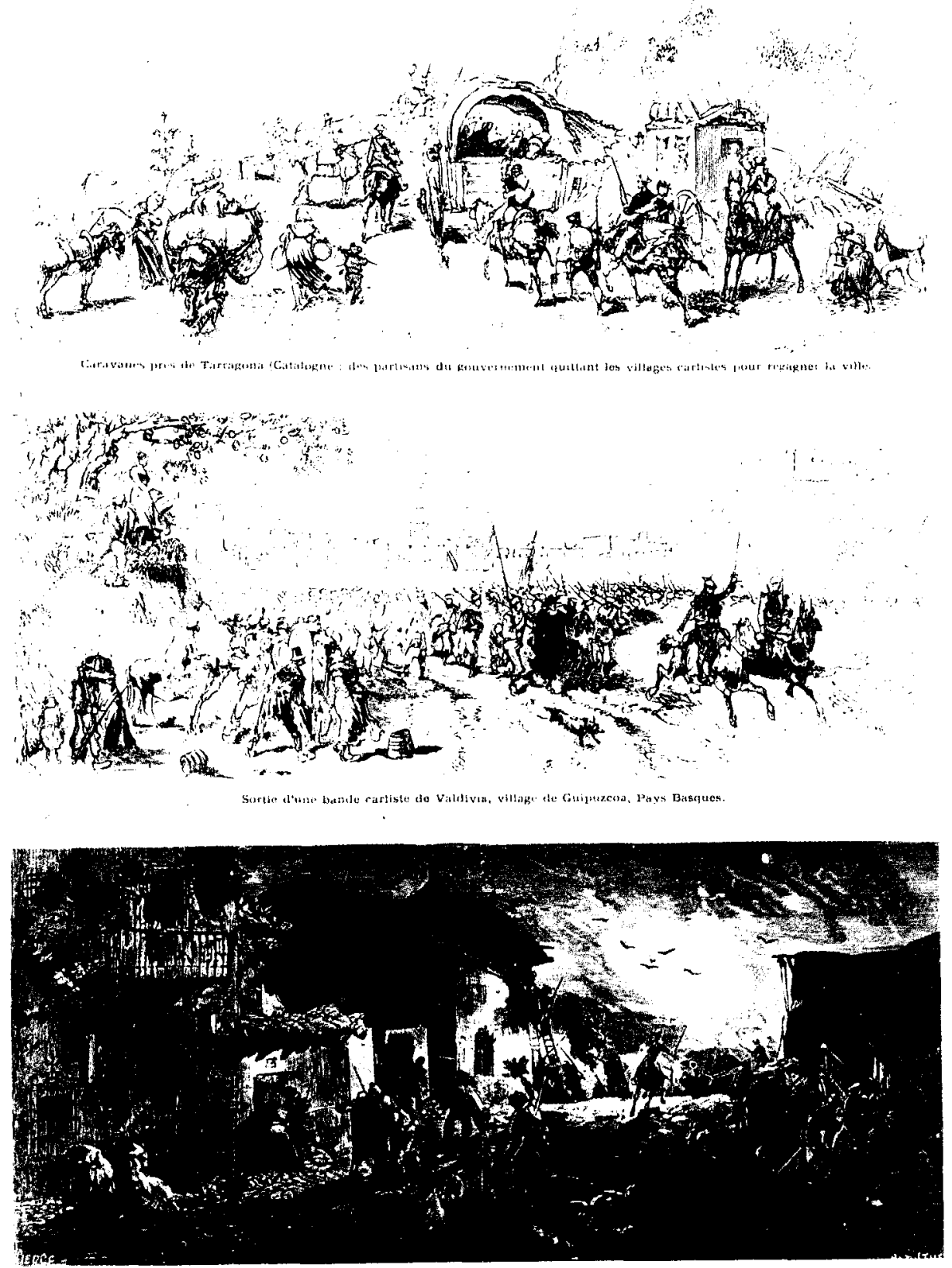

Fig. 4. Le Monde Illustré, mayo 4, 1872. 

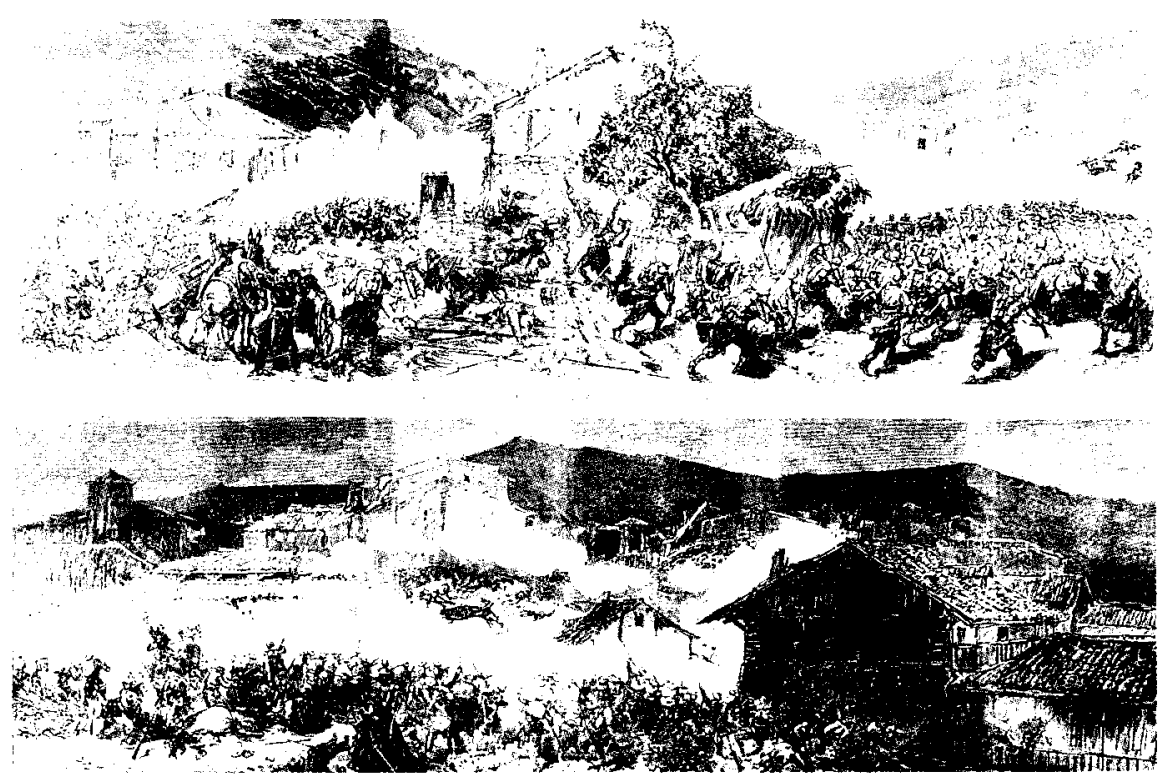

Fig. 5. Le Monde Illustré, mayo 18, 1872.

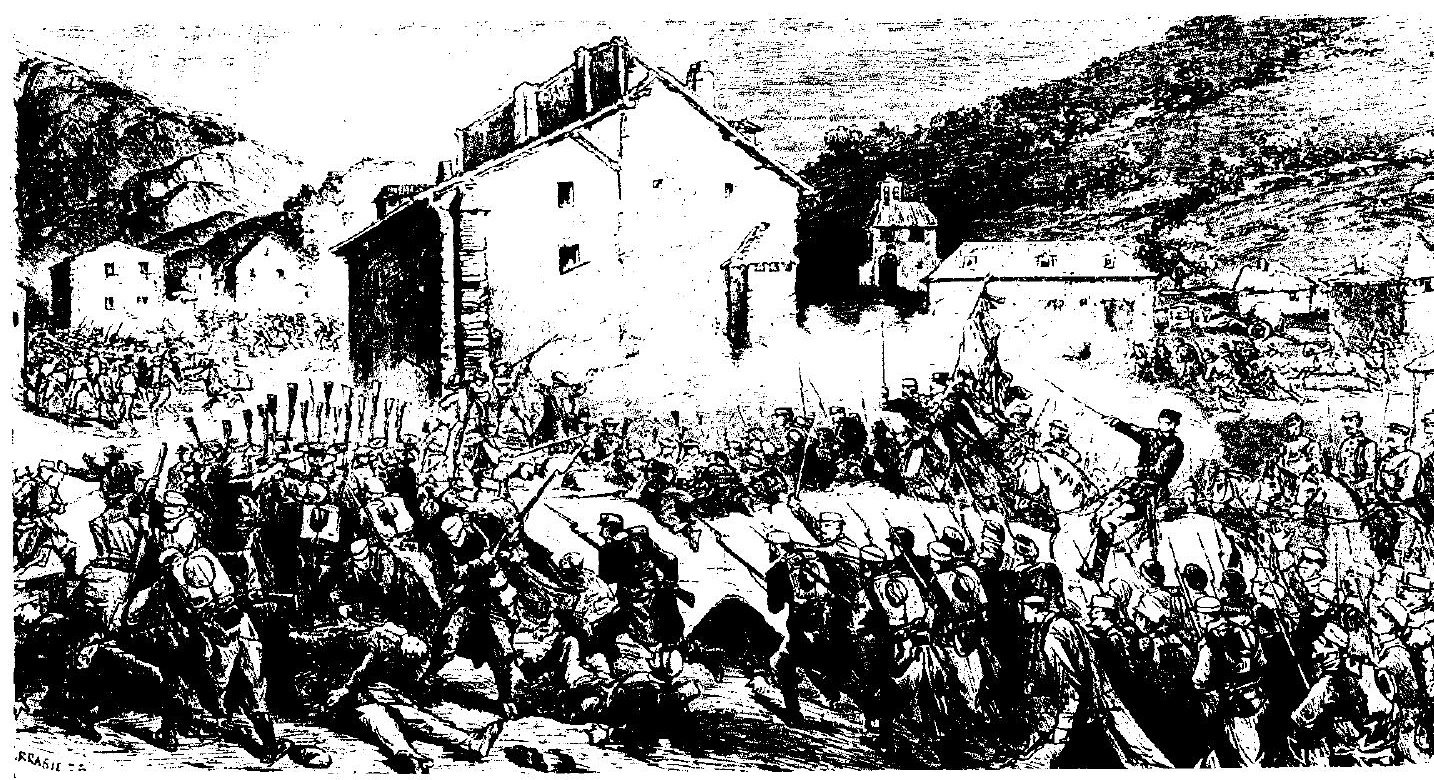

Fig. 6. Ilustración Española y Amaricana, mayo 18, 1872. 
Ciertos grabados ("Reddition de la Seo de Urgel», 11 de septiembre de 1875) (Fig. 7) muestran una iconografía de España como "conventocuartel». El día 26 de agosto de 1875 terminó el sitio de Urgel, cuando Lizárraga y el obispo tuvieron que rendirse, por sed, con más de 1.000 hombres, a los que Martinez Campos y Jovellar, comprometidos a no enviarlos deportados a Cuba, concedieron todos los honores de la guerra. La estampa recoge el momento en que las tropas carlistas desfilan ante los vencedores liberales, a quienes el obispo de la Seo, Caixal y Estrade, imparte la bendición. Desarmada la guarnición, el obispo fue desterrado a Roma. Caixal, el eclesiástico de mayor dignidad en la causa de Don Carlos, proclamaba en una pastoral que no habia sido Espartero, sino la ira de Dios, la que habia arrojado a los carlistas a la frontera en la guerra de los Siete Años, y ahora pasaba lo mismo por ir tras el poder, y no tras la victoria de Dios, del Rey y de la Patria...

Rasgos como los apreciados en estos grabados configurarían una imagen peculiar de España, como la que habían percibido los viajeros románticos del primer tercio del XIX, imagen que Vierge refleja de nuevo a finales de siglo. Sin duda, la realidad social prestaba todavia base a esta percepción. "En las Cortes Constituyentes de 1869 el canónigo

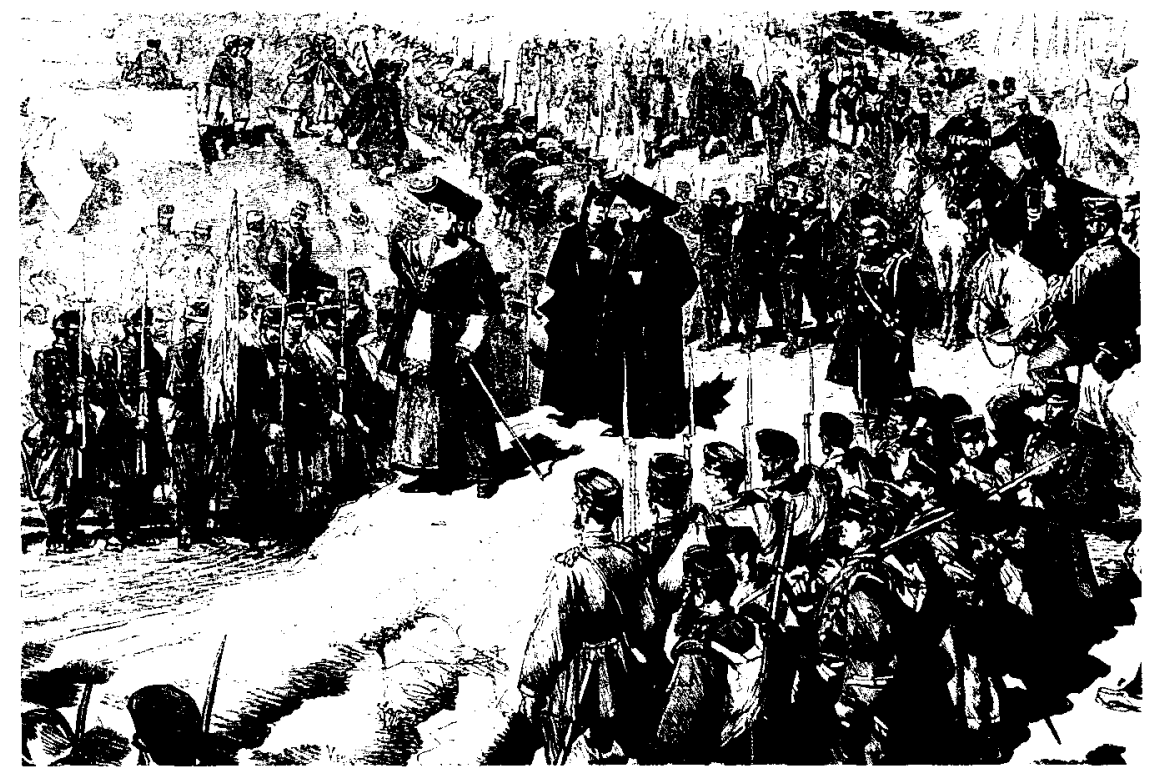

Fig. 7. Le Monde Illustré, septiembre 11, 1875. 
Manterola había asegurado que la mayoría de los campesinos guipuzcoanos seguia pagando diezmos, nada menos que treinta años después de que hubieran sido abolidos" "'. Ayala ha señalado como tras la Contrarreforma «Europa debía de contemplar a España como una nación enajenada" "2. Pues bien, ahora, bajo la influencia del "Volksgeist, con el consiguiente entusiasmo por todo lo pintoresco, peculiar y particularista» ${ }^{13}$, los curas carlistas, que tomaban tan en serio su papel beligerante en defensa de la causa legitimista, cometiendo todo tipo de tropelías ${ }^{14}$, debían de aparecer como una manifestación genuina de nuestro espíritu nacional.

Y no obstante, no es posible desechar que las publicaciones gráficas extranjeras gustasen de prodigar la imagen pintoresca acuñada por los escritores franceses y los turistas ingleses de la anterior generación. Aunque la base de los dibujos de Vierge está tomada "d'aprés nature" por los corresponsales de Le Monde Illustré, se desprende de aquéllos una cierta impresión de realidad mediatizada, bien por el mismo Vierge, inclinado a la escena vistosa ${ }^{15}$, bien por la dirección de la revista, la cual, a diferencia de una publicación coetánea, La Ilustración Española y Americana, omitía mostrar los aspectos sociales de la guerra, las penalidades de los soldados, sus tareas fuera de los momentos de acción, fijándose tan sólo en aquello que parecía vender más: las singularidades propias de una cultura «primaria».

\section{LA TRADUCCIÓN EXACTA DEL GRAFISMO DE VIERGE}

Para un medio donde la imagen formaba parte esencial de la información, la preocupación por el dato visual preciso, manteniendo la fidelidad del detalle iconográfico del original, y acelerando al mismo tiempo el proceso de publicación, fue constante. Los ensayos de Le Monde Illustré, semanario pionero en los métodos de reproducción fotomecánica, no cesaron desde 1874. A partir del 21 de noviembre de ese año hasta el 4

11 Andres Gallego, José, "Sobre las formas de pensar y de ser", en Historia General de España y América", Tomo XVI-1. Madrid, Rialp, 1982, pág. 284.

12 Ayala, Francisco, La imagen de España. Madrid, Alianza, 1986, pág. 82.

13 AYALA, Francisco, obra citada, pág. 15.

14 Caravaca, F., y Orts-Ramos, A., Historia llustrada de la Revolución Española 1870 1931. Barcelona, Iberia-Muntaner, 1932, pág. 133.

15 Menéndez-Pidal, Gonzalo, La España del siglo xix vista por sus contemporáneos. Tomo I. Madrid, Centro de Estudios Constitucionales, 1988, pág. 25. 
de marzo del 76 (la guerra finalizó en febrero) hemos contabilizado trece fotograbados, de los que seis aluden al conflicto carlista.

La revista, interesada en ofrecer a sus lectores estos primeros perfeccionamientos de la industria francesa, comenzó por utilizar la zincografia o fotograbado de línea, sólo aplicable en dibujos lineales. En la nueva técnica «las planchas están revestidas con alguna sustancia coloidal bicromatada que endurece al ser expuesta a la acción de la luz. La plancha es expuesta debajo de un negativo" ... y «lavada con agua que disuelve la parte del revestimiento no endurecida por la acción de la luz que atravesó el negativo .... A continuación se trata la plancha con una sustancia resistente a los ácidos ... Después es introducida en un baño de ácido que "muerde" los espacios entre líneas" ${ }^{16}$.

Los fotograbados de Vierge sobre la guerrra carlista nos permiten un acceso directo a su grafismo temprano. Se ha dicho que "fué probablemente en 1876 cuando Vierge comenzó a dibujar con pluma y tinta los delicados bocetos, acentuados con manchas negras, que iban a quedar tan afortunadamente asociadas a su nombre " ${ }^{17}$. Pues bien, tales manchas, en contraste con un sombreado de tonos grisáceos y claros, que crean así el volumen de las figuras, se aprecian ya en las viñetas de "Voyage du roi Alphonse XII dans le Nord", que datan del 13 de febrero de 1875 (Fig. 8). La reproducción xilográfica no permitía apreciar lo que aquí es posible: la uniformidad del trazo de Vierge, tan característica de sus posteriores ilustraciones, como las realizadas para la edición francesa del Buscón de Quevedo, "primer libro ilustrado con aguafuertes fotomecánicos en relieve, que salió a la luz en $1881{ }^{18}$. La estampa recoge diversas etapas del viaje del rey al campo de operaciones del Norte, para organizar la guerra contra Don Carlos.

La aplicación de la fotografía al grabado nos permite también contraponer las maneras dibujísticas de los dos grandes ilustradores de este conflicto. Bajo el título "Types et épisodes de la guerre civile", 19 de febrero de 1876 (Fig. 9), Pellicer, corresponsal del semanario francés por estas fechas, se propone en su croquis captar los tipos de fisionomia, indumentaria y acontecimientos más populares de la guerra carlista. Aunque retocado por Vierge, el dibujo respeta el estilo sobrio y realista de Pellicer, tan obsesionado por el control de su obra; el arte vitalista de

16 IVINS, William M., Imagen impresa y conocimiento. Analisis de la imagen prefotogràfica. Barcelona, Gustavo Gili, 1975, pág. 177

17 Du Gué Trapier, Elizabeth, Daniel Urrabieta ..., pág. XII.

18 IVins, William M., obra citada, pág. 177. 


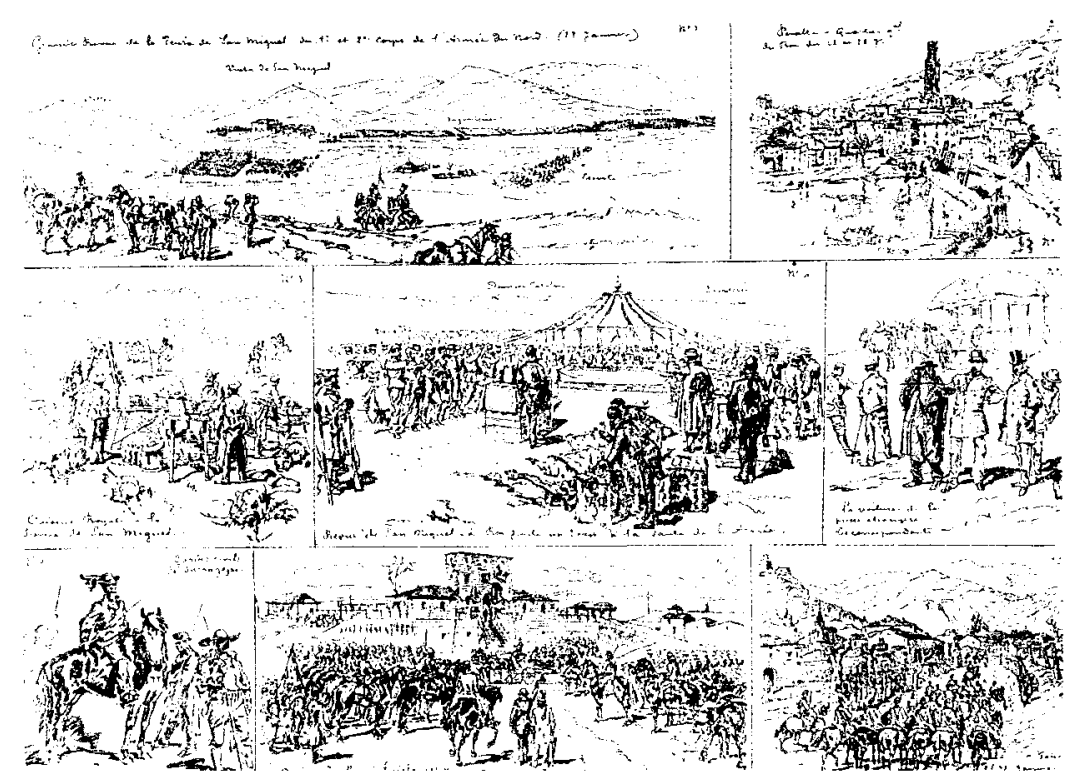

Fig. 8. Le Monde Illustré, febrero 13, 1875.

aquél queda oculto tras el estatismo, y el interés por las personas, de éste. Cabe, por tanto, aventurar que la reconocida influencia de Vierge sobre Pellicer ${ }^{19}$ fué de hecho recíproca.

Emilio Bergerat ${ }^{20}$ cuenta como vio imprimir un dibujo de Daniel para Le Monde Illustré usando una variante del fotograbado de línea, sobre la técnica del «gillotage", inventada por Firmin Gillot. "Charles, hijo del inventor, grabó una plancha de cinc siguiendo el proceso de su padre, que él habia ido perfeccionando; y, cuando la plancha salió del baño de nitrato, sacó una prueba sobre papel de India con una prensa de mano. Era tan exacta, y tan parecida al original, que no se podia distinguir la una de la otra» ${ }^{21}$. Ésta es la técnica usada en "Les carlistes battus à Mon-

19 Fontbona, Francesc, "La ilustración gráfica. La técnicas fotomecánicas", en El Grabado en España (siglos $x i x$ y $x x$ ), Summa Artis, Vol. XXXII. Madrid, Espasa Calpe, 1988. pág. 446.

20 Bergerat, Emile, Souvenirs d'un enfant de Paris. Paris, 1912, V. 3, pág. 87; citado en Du Gue Trafier, Elizabeth: Daniel Urrabieta ..., pág. XVI.

21 En el gillotage primitivo se transfería el dibujo, de una piedra litográfica a la plancha de cinc, por simple aplicación de presión. No era posible, sin embargo, reproducir los sombreados característicos de la litografia (PASSERON, Roger, Daumier. Témoin de son temps. Friburgo, Office du Libre, 1986, pág. 288). 
La campaña carlista (1872-1876) en Le Monde Illustré: los dibujos ...

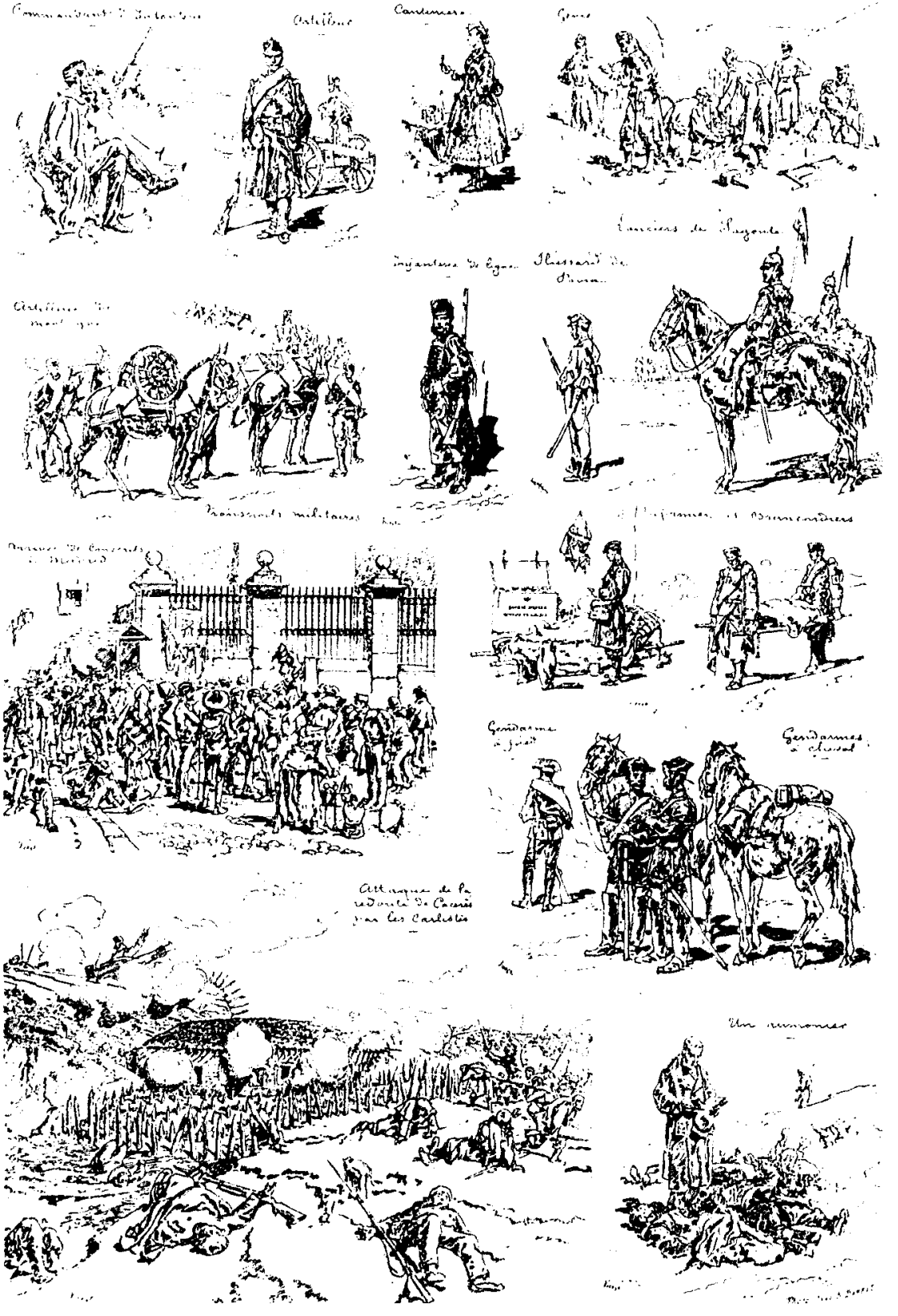

Fig. 9. Le Monde Illustré, febrero 19, 1876. 


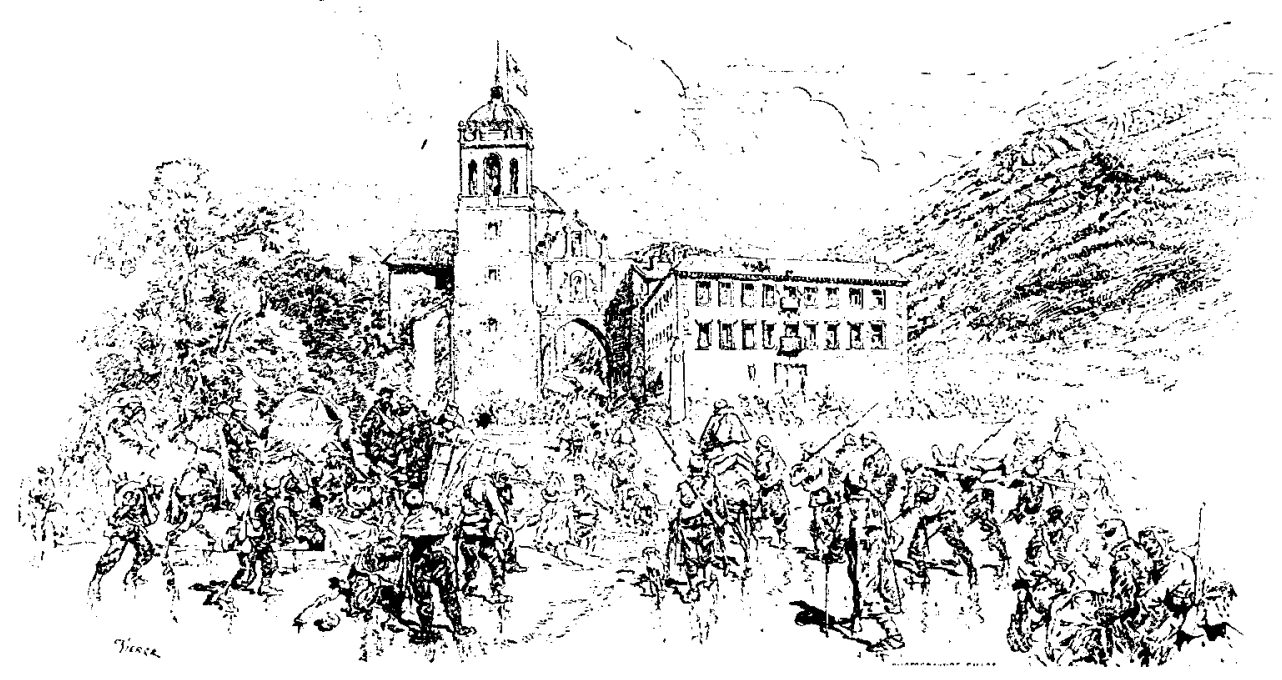

Fig. 10. Le Monde Illustré, marzo 4, 1876.

tejurra", 4 de marzo de 1876 (Fig. 10). En ésta, como en las anteriores estampas de los comienzos del fotograbado de línea, se observan ciertas irregularidades en la textura del papel, causadas probablemente por la dificultad en regular la presión a ejercer sobre el nuevo tipo de matriz. La voluntad de vivir de estos heridos a pie, en andas, o a caballo, evoca la que demostraría Vierge en 1881 al quedar hemipléjico de su lado derecho, y tener que aprender a dibujar de nuevo con la mano izquierda.

\section{LA FURIA DE LAS BATALLAS}

La factura dibujistica de Vierge se aprecia sobre todo en los múltiples grabados de escena bélica. El número de éstos, cuando se compara con el publicado en otras revistas de la época, manifiesta, por otra parte, el interés del artista por el dibujo de acción. "Le combat de Manaria", 1 de junio de 1872 (Fig. 11), iniciado con el ataque de carlistas emboscados a una avanzada de la división Letona que portaba bandera blanca, es una bella estampa de figuras apoyadas sobre un pié, que permite a Vierge realizar un extraordinario estudio del equilibrio, motivo que más tarde 


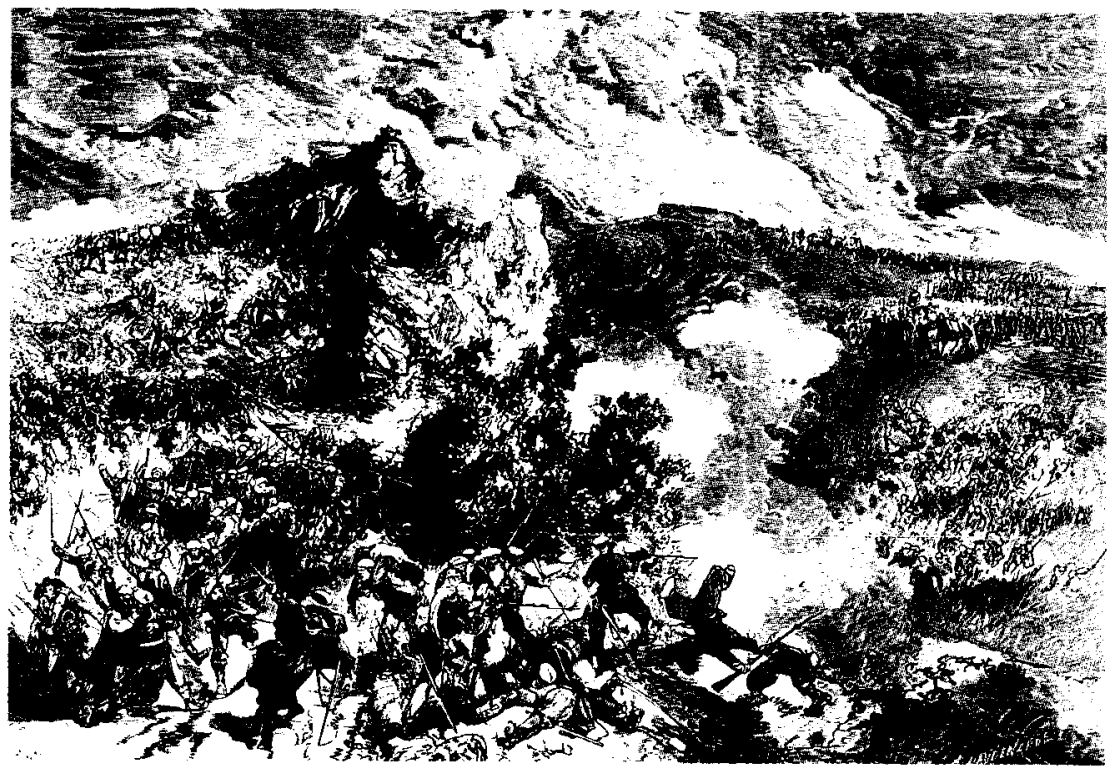

Fig. 11. Le Monde Illustré, junio 1, 1872.

recogerá la xilografía japonesa en los dibujos sobre la guerra de fin de siglo entre China y Japón ${ }^{22}$. La composición de la escena recuerda un cuadro, hay un afán de rellenar toda la estampa sin dejar espacio vacío. La curiosa manera con que Vierge enfatiza y contrasta espacios en negro intenso, blanco y gris, convierte en arte la simplicidad y rigidez lineal usuales en este tipo de ilustración.

En «Le combat d'Onate, près Bilbao», 15 de junio de 1872 (Fig. 12), Vierge da rienda suelta a su imaginación. El dibujo es vibrante y etéreo: los carlistas cayendo en el vacío, el fogonazo de los fusiles en la ventana enrejada, el rostro angustiado del fraile, la banda marchando directamente al agua y los cornetas emergiendo de ella. La composición es de una gran complejidad y la factura recorre toda la gama desde el preciosismo de las figuras en primer plano hasta el trazo abocetado de las masas de soldados que surgen al fondo. Representa el momento del asalto a la plaza de la villa por los cazadores de Mendigorria; los carlistas, cuyo jefe

22 KeEgan, John and Darracott, Joseph, obra citada, pág. 192. 


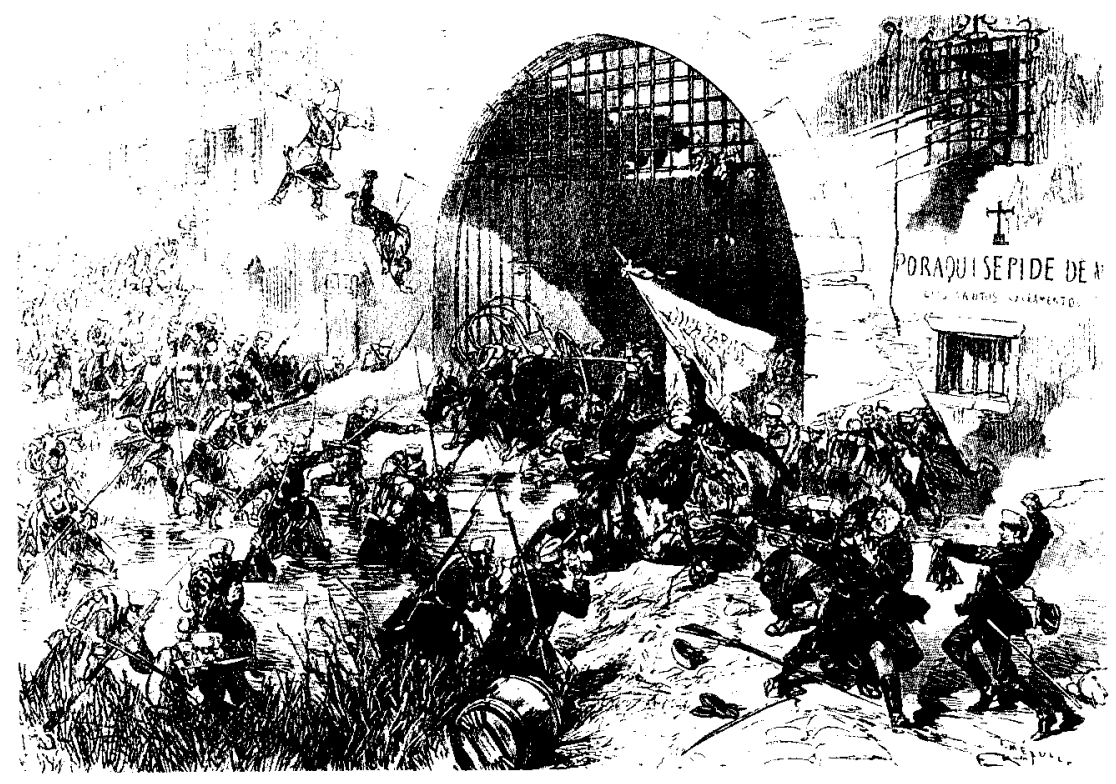

Fig. 12. Le Monde Illustré, junio 15, 1872.

Ulibarri fue herido en la refriega, se habian refugiado en un antiguo convento. El brazo del río bajo su arcada confiere un carácter singular al grabado.

Uno de los hechos de mayor relevancia histórica en la iconografía bélica de este conflicto fue la muerte del general Concha, el jefe liberal de mayor prestigio militar. El grabado de Le Monde Illustré, "Bataille de Muro.-Après la mort du marèchal Concha, la cavalerie espagnole enlevé son corps aux carlistes", 11 de julio de 1874 (Fig. 13), es una escena teatral, como un cuadro de la coetánea pintura de Historia, documentado aqui sobre informes enviados por un oficial ${ }^{23}$. Vierge solemniza el mo-

23 La crónica francesa cuenta cómo el 27 de junio el general Veja Juclan había escrito a su mujer, a las once de la mañana, que por la tarde lo haría ya desde Estella. Concha, acompañado de sus ayudantes, se acercó tanto a las primeras posiciones, donde el tiroteo era muy intenso, que podia oír los insultos y las balas. El general, corto de vista, preguntó si los soldados que avanzaban eran sus tropas o las carlistas. No hubo mucho tiempo para dudas. Una bala arrancó la nariz del ayudante de campo, y otra atravesó el pecho de Concha cuando, con la mano en la crin y el pie en el estribo, intentaba subir a su caballo. 


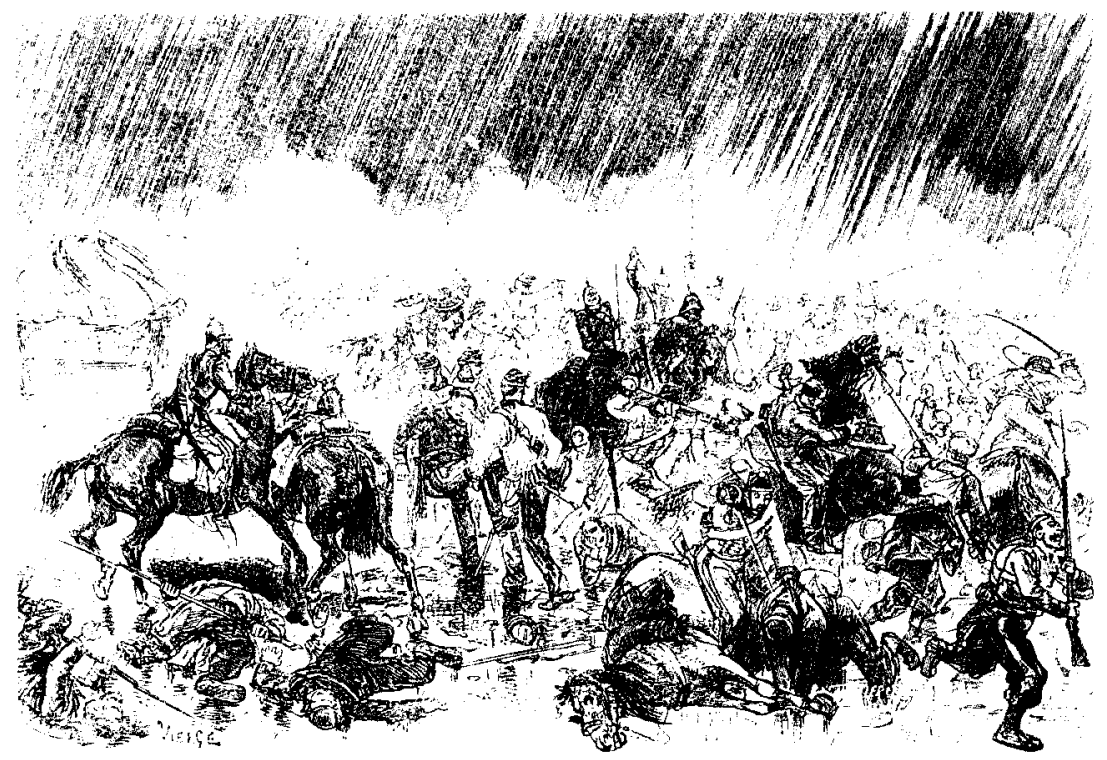

Fig. 13. Le Monde Illustré, julio 11, 1874.

mento recurriendo a un cielo oscuro arreciando lluvia, a una caballería enloquecida, y a la crueldad de unos soldados con tintes de la España Negra. Ante la puntilla al enemigo derribado, o la espada que se hunde en el rostro del carlista, cabe la ironía de Unamuno: "Los pueblos necesitan algo viril para no caer en la molicie. El pueblo de pan y toros fue el que supo dar cara a Napoleón ${ }^{24}$.

Todavía más teatral es la ilustración que, sobre la muerte del Marqués del Duero, publico la revista americana Harper's Weekly. The death of Marshal Concha, 8 de agosto de $1874^{25}$. Por el contrario la versión aparecida en La Ilustración Española y Americana, "Gloriosa muerte del Sr. Marqués del Duero', 8 de julio de 1874 (Fig. 14), basada en un croquis de un testigo presencial, tienen un aire de veracidad periodistica. De hecho, el cielo aqui está claro: The Illustrated London News narra

24 Unamuno, Miguel de, obra citada, pág. 248.

25 Bastida de LA CALLE, M. Dolores, “lmagen de la última guerra carlista en las revistas norteamericanas de la época". Goya, núm. 215 (1990), págs. 264-268. 


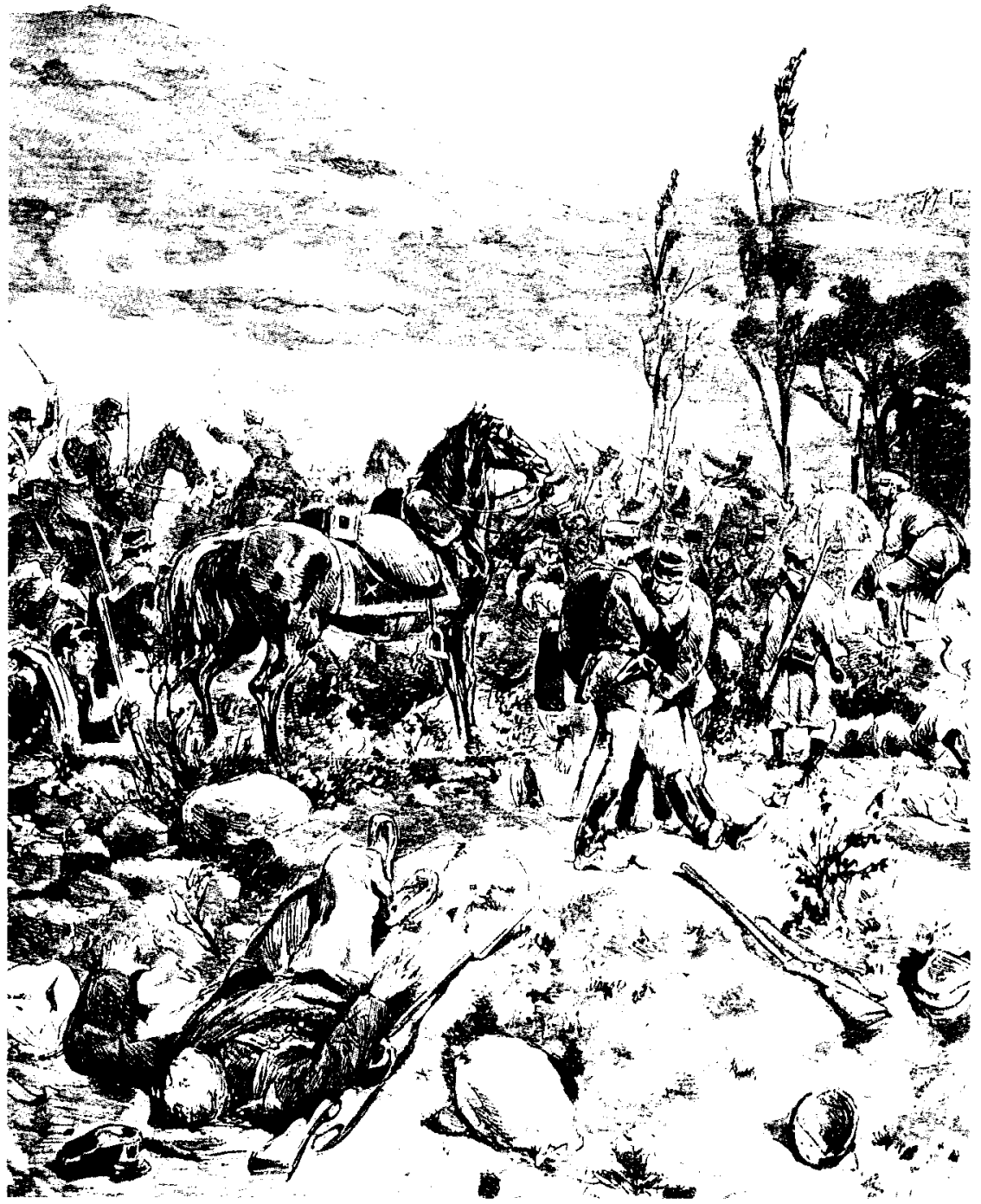

Fig. 14. I/ustración Española y Americana, Julio 8, 1874. 
cómo la lluvia no comenzó hasta horas después de producirse la muerte ${ }^{26}$.

El grabado "Prise de Cuenca par les carlistes (Nouvelle-Castille)", 1 de agosto de 1874 (Fig. 15) exhibe de nuevo una hostilidad de trágico humor negro entre los soldados. No hay duda de la raíz esencialmente española del arte de Vierge, que tiene su primer modelo en Goya ${ }^{27}$. La barbarie de Cuenca, trajo a la memoria de las gentes contemporáneas las disculpas de Balmes sobre el salvajismo de las corridas de toros: nuestro corazón «al mismo tiempo que abriga la compasión más tierna por el infortunio parece que se fastidia si tarda largo tiempo en hallar escenas de dolor, cuadros salpicados de sangre" ${ }^{28}$. La tensión y el movimiento, como en otras ocasiones, es el leit motiv del lenguaje gráfico de Vierge. No menos movido fue el hecho histórico. El día 13 de julio de 1874 las facciones reunidas de Aragón y Valencia, al mando del infante don Alfonso, rodearon la ciudad de Cuencia, y a las cuatro de la madrugada comenzó el ataque. Los asaltos se repitieron los días catorce y quince, cuando las tropas carlistas, formadas por zuavos pontificios, cantonales de Alcoy, fugitivos de la Comuna y ex-presidiarios, lograron apoderarse de la ciudad. Parece que doña Blanca paseó la bandera por una ciudad asustada por el furor de estos aventureros mercenarios, aunque la historiografía carlista ha hecho algunas puntualizaciones ${ }^{29}$.

Un motivo muy expresivo del talento artístico de Vierge, es la variedad en el entintado y en el tamaño de las figuras. En «Prise de Biurrum par le brigadier Perula», 7 de noviembre de 1874 (Fig. 16), el artista recrea multitud de figuras en miniatura, sobre un paisaje localista de aldea, que contrastan con los soldados fuertemente entintados en torno al escribano de Corella, José Perula, general en jefe del ejército del Norte tras una intensa, pero breve campaña de voluntario en África. Por el contrario hay poco de su arte en el "Combat d'Urnieta", 23 de enero de 1875 (Fig. 17) ${ }^{30}$. El grabado nos recuerda ciertas estampas carlistas del

${ }^{26}$ The illustrated London news, 11 de julio de 1874, pág. 37.

27 BELLO, Luis, “Un gran ilustrador, en memoria de Urrabieta Vierge", La Esfera, agosto 17. 1929, págs. 34-35. Con seguridad, el artista conoció "Los desastres de la Guerra" durante sus estudios en la Academia de Bellas Artes de San Fernando en 1864. (GuSman, Pierre, obra citada, pág. 122).

${ }^{28}$ BALMES, Jaime, El protestantismo comparado con el catolicismo, obras completas, vol. IV. Madrid, Editorial Católica, 1967, pág. 295.

29 Oyarzun, Román, Historia del carlismo. Madrid, Pueyo, 1965, pág. 343.

${ }^{30}$ Oyarzun cuenta cómo el general Loma, con 12.000 hombres en tres columnas, salió el ocho de diciembre de su encierro en San Sebastián para romper el cerco carlista. En el asalto a Urnieta fueron heridos Loma y el general carlista Diez Mogroviejo, que comandaba el batallón de Guias del Rey que hizo retirar a los liberales al abrigo de sus fuertes. (OYARzun, Román, obra citada, pág. 307). 


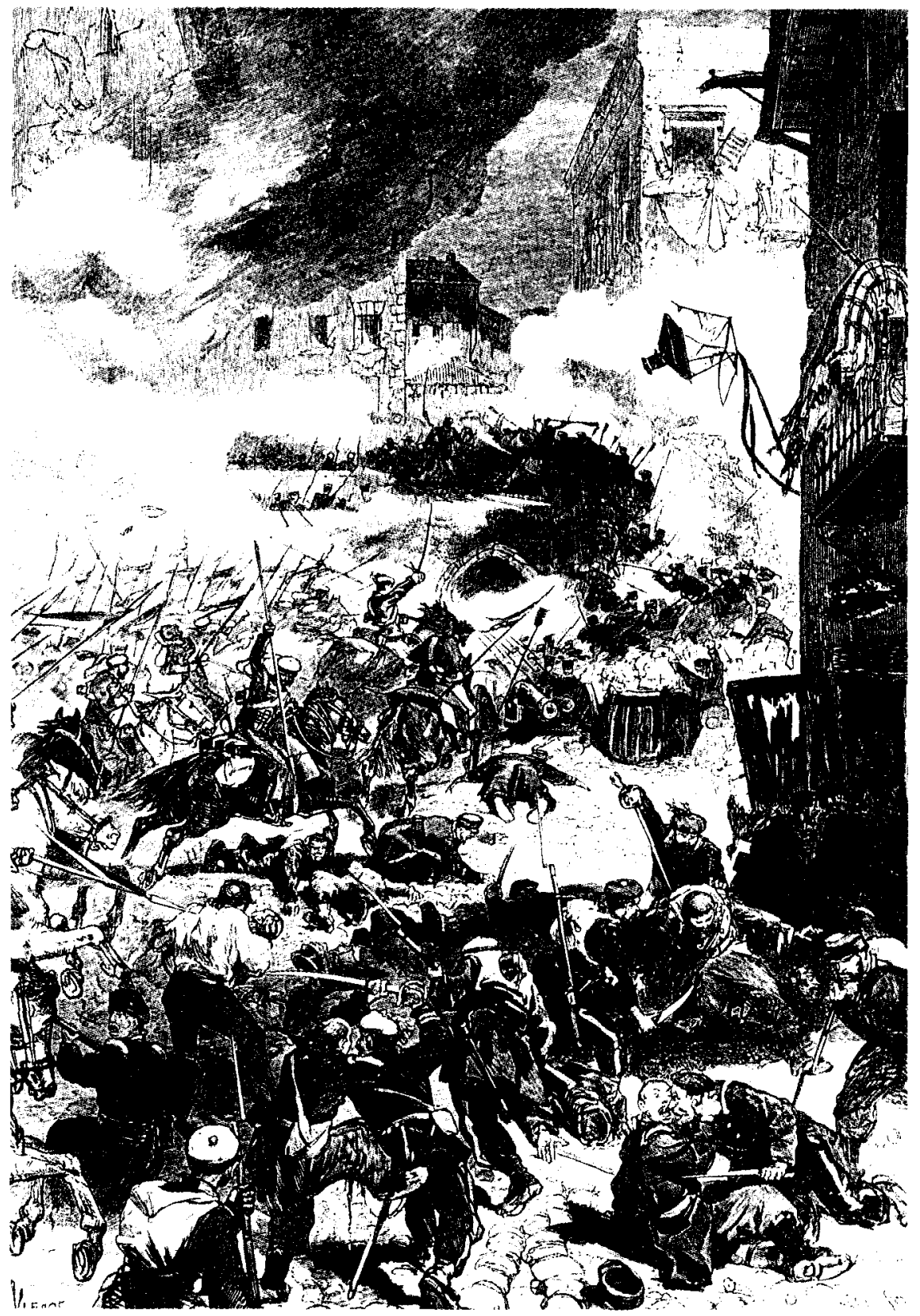

Fig. 15. Le Monde Illustré, agosto, 11874. 


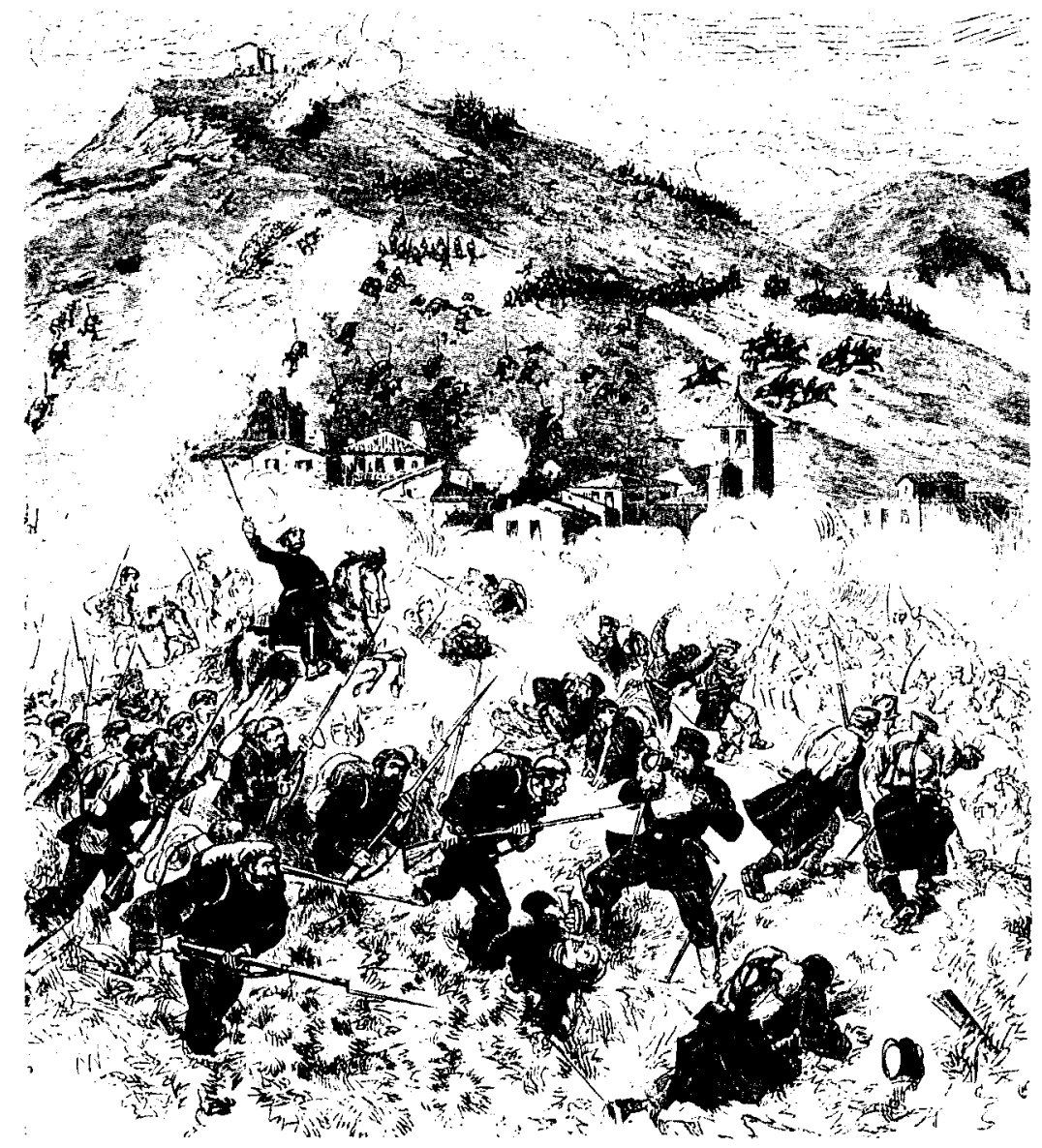

Fig. 16. Le Monde Illustré, noviembre 7, 1874.

Illustrated London News, reflejo de la estandarización del trabajo lineal de los grabadores de este tipo de revistas, que llega incluso, como aquí, a desvanecer la personalidad del dibujante.

A un mes de finalizar la guerra, una guerra que se acaba por consunción, el 25 de enero por la mañana, las tropas liberales, que formaban las divisiones Cuachos y Morales de los Rios, atacaron las primeras líneas de defensa carlista ante Hernani y Oyarzun, tomadas finalmente hacia el mediodia. La complejidad escenográfica en "Prise de la redoute de Gavate", 26 de febrero de 1876 (Fig. 18) recuerda a Delacroix en su 


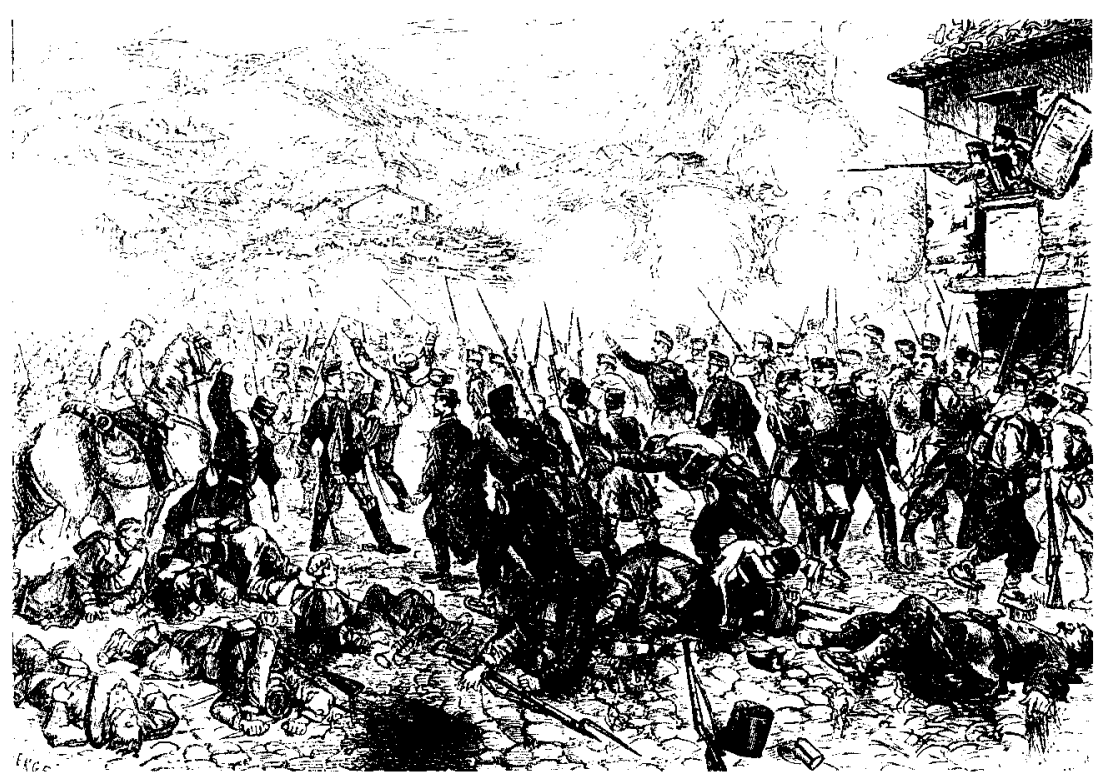

Fig. 17. Le Munde Illustré, enero 23, 1875.

óleo "La muerte de Sardanápolo»; las figuras aquí como alí parecen resbalar y evidencian el tipo de composición con extremos poco definidos, característico de la viñeta y adoptado con frecuencia por la pintura romántica ${ }^{31}$. Es claro el interés de Vierge por esa viñeta romántica con sketches o bocetos entremezclados, sin delimitar ("Siège de Puigcerdá", 19 de septiembre de 1874) (Fig. 19), un tipo de grabado que permite la selección de episodios escogiendo los momentos más decisivos. El lenguaje caligráfico difiere aquí de unos sketches a otros. En la parte superior la factura es fina, suave, de delicadeza japonesa; el sombreado de la figura central, el comandante de la plaza Andrés Morella, a base de rayas y garabatos, nada tiene que ver con el sombreado de líneas inclinadas y paralelas usual en la ilustración de actualidad. Un despacho del 10 de abril anunciaba que los carlistas, al mando de don Alfonso de Borbón y del cabecilla catalán Savalls (el demonio de las cruces, el segundo Cabrera para los liberales), habian abierto fuego contra Puigcerdá. Martínez Campos les obligó a levantar el bloqueo. Parece que las dife-

${ }^{31}$ Rosen, Charles y Zerner, Henri, Romanticismo y Realismo. Los Mitos del arte del siglo xix. Madrid, Hermann Blume, 1988, pág. 101. 


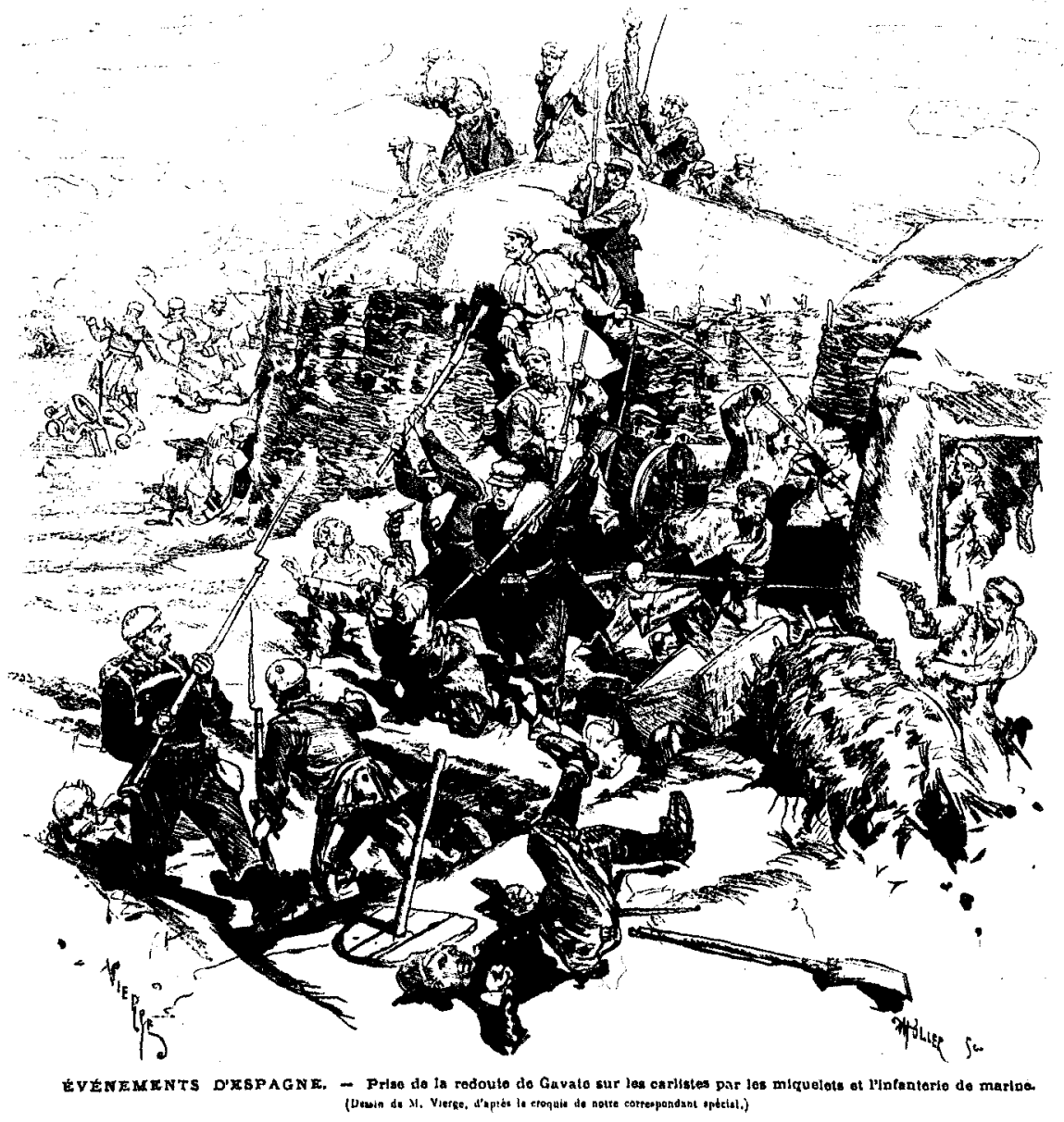

Fig. 18. Le Monde Illustré, febrero 26, 1876. 


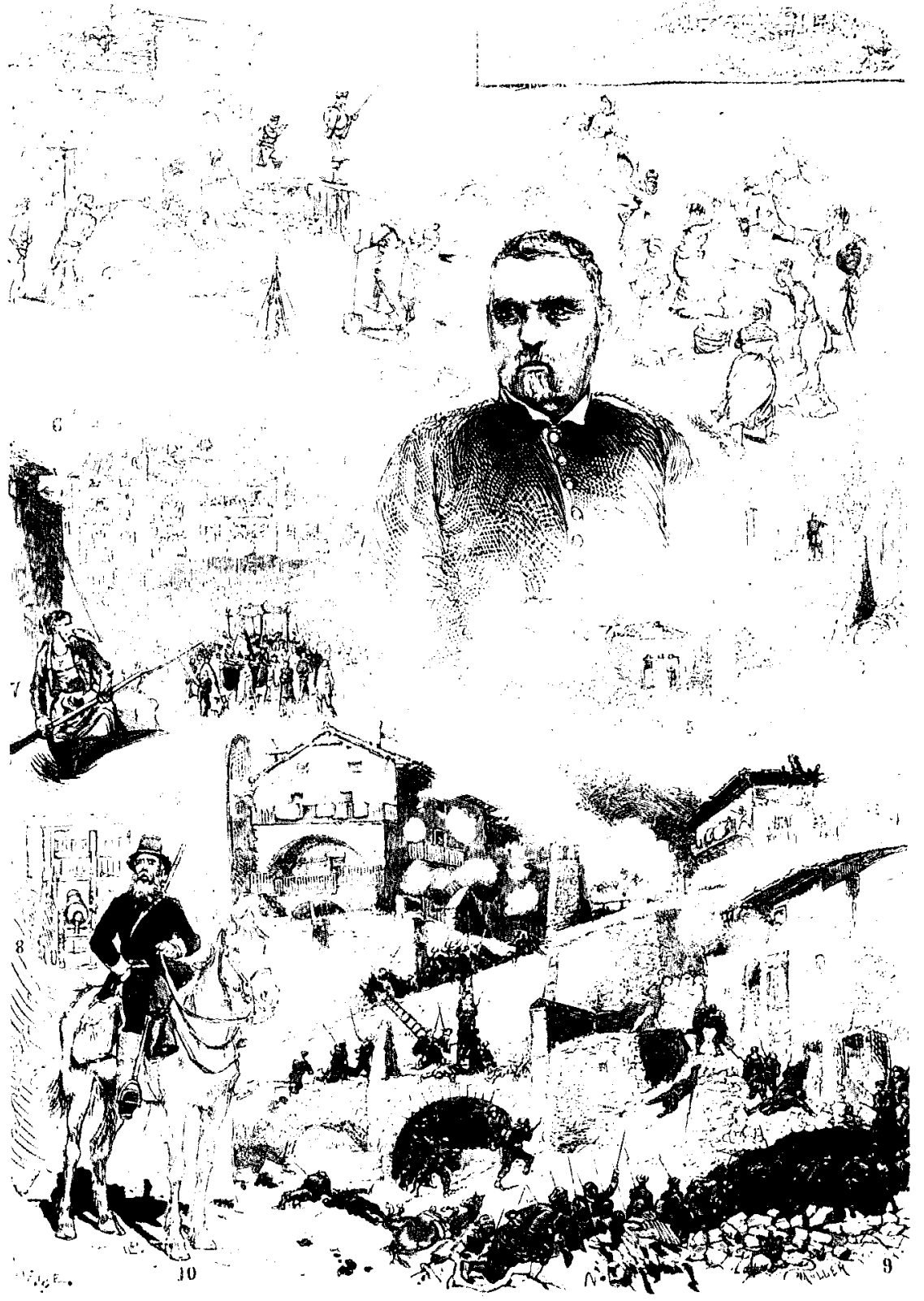

Fig. 19. Le Monde I/lustré, septiembre 19, 1874. 
rencias entre Savalls y don Alfonso fueron grandes, lo que contribuyó a enfriar las relaciones de éste con don Carlos, quien no quiso en manera alguna desprenderse del caudillo catalán.

\section{LA ALEGRIA EN LAS CELEBRACIONES}

Es posible aventurar que el carácter festivo, y la vistosidad escénica que se aprecia en muchos grabados de Vierge se deba a su condición de artista de estudio, alejado de las atrocidades de la guerra. El contraste con los grabados de José Luis Pellicer, entonces corresponsal de La I/ustración Española y Americana en el conflicto carlista, siempre en la primera línea de los horrores, es revelador ("Entrée des troupes espagnoles à Bilbao", 30 de mayo de 1874 y "Bilbao._Dos de Mayo: Entrada del ejército libertador", 15 de mayo de 1874) (Figs. 20 y 21). Obsérvese el gesto grave y serio de la guardia civil en la revista española, tan en consonancia con el tremendismo y preocupación social de Pellicer ${ }^{32}$. El grabado de Vierge, por el contrario, es todo él una explosión de gozo, un festejo. A la una de la tarde del 2 de mayo, el general Concha, al frente del tercer cuerpo, con los carabineros y guardias civiles que se habian destacado en los últimos combates en primera línea, entró en Bilbao por el puente de Isabel II y la calle de la Estufa. Los balcones y miradores de las casas estaban cubiertos de ricos tapices y telas con los colores nacionales, y damas elegantes agitaban los pañuelos y arrojaban sobre los soldados ramos de flores y coronas. Vierge recurre a la vegetación, aqui arrancada de la naturaleza: los soldados adornados con coronas, las flores en las puntas de las bayonetas y la niña arrojándolas de un cesto.

La estampa de "Santander à Saint-Sébastien, de Saint-Sébastien à Santander», 12 de diciembre de 1874 (Fig. 22) vuelve a ofrecernos un mensaje gráfico de optimismo: el lector de periódico tumbado, el grupo de danzantes, las charlas de corros o parejas de amigos, la banda tocando incansablemente. Pero también los solitarios en la borda, o el soldado desconfiado, que comprueba sus bultos. El observador está en lo alto de un mástil, lo que permite mostrar la vista abigarrada de la cubierta del barco. En el grabado no hay nada estático, todo es movi-

32 Bastida de la Calle, M. ${ }^{a}$ Dolores, "José Luis Pellicer, corresponsal artístico en la última guerra carlista", Espacio, Tiempo y Forma, núm. 2, 1990, pags. 343-375. 


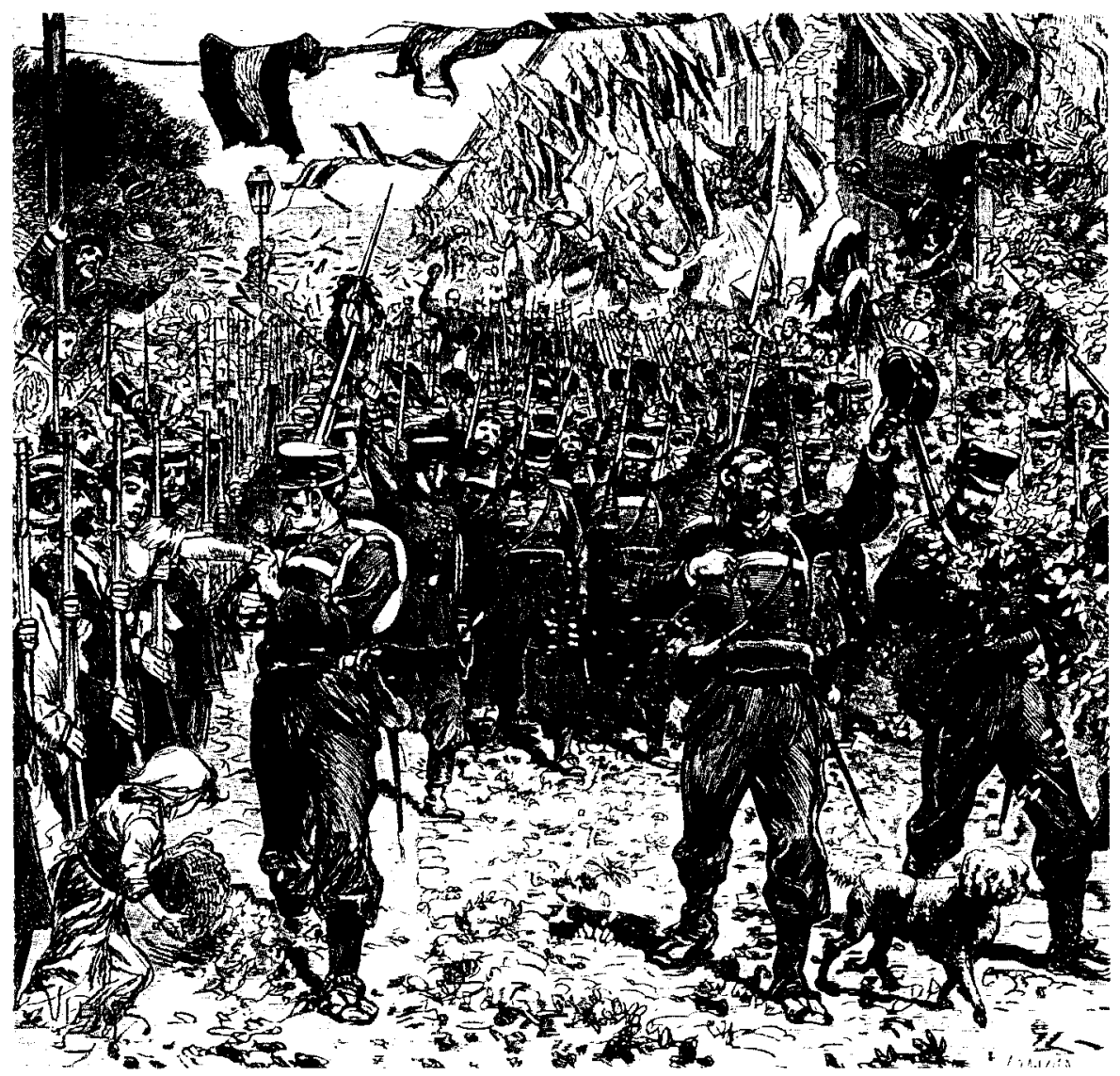

Fig. 20. Le Monde Illustré, mayo 30, 1874.

miento, vitalismo. Véanse los gestos de los personajes charlando y las ondulaciones de los uniformes de los soldados.

"Le Somaten», 18 de diciembre de 1875 (Fig. 23) retrata al lector la España singular y pintoresca. La escena nos pinta un aspecto de la guerra en un pueblo pequeño, donde el elemento festivo es el dominante. La toma de la Seo de Urgel, principal plaza insurgente en Cataluña, fue un duro golpe para la causa carlista. Columnas volantes organizadas por el general Martinez Campos, recorrian el pais de punta a punta, en busca de restos de las antiguas bandas de Savalls y Tristany, y les obligaban 


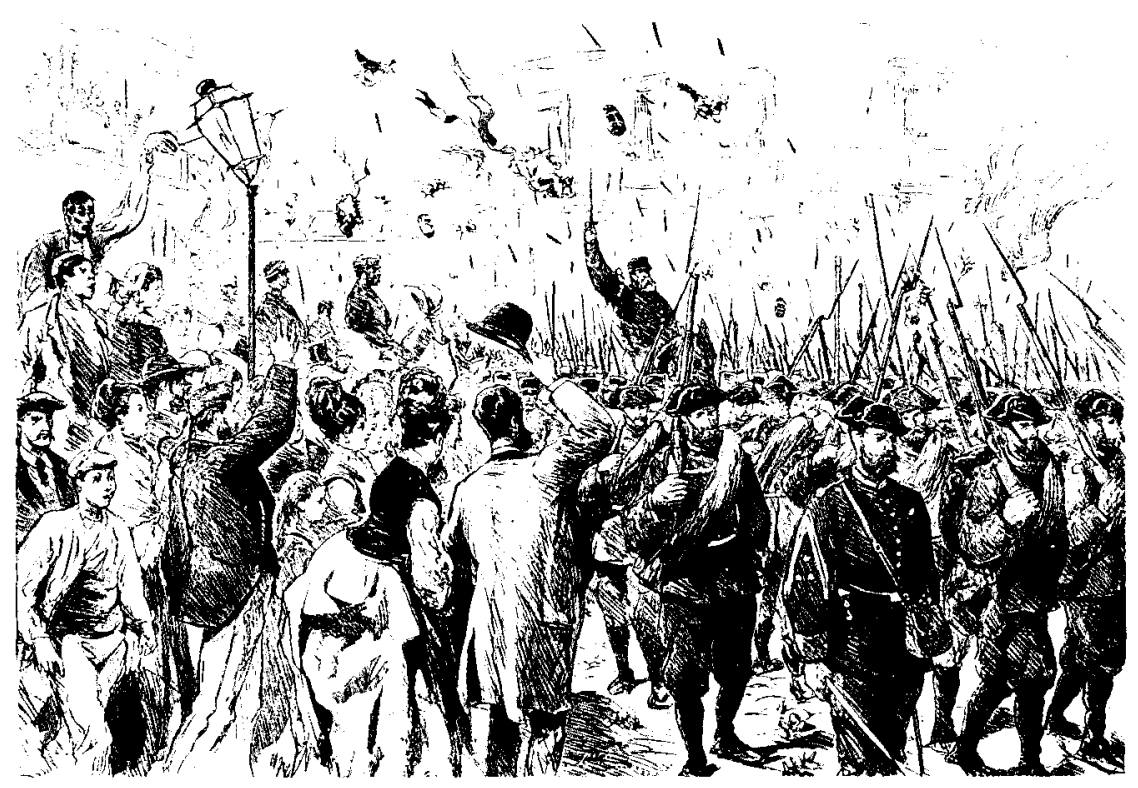

Fig. 21. Ilustración Española y Americana, mayo 15, 1874.

bien a deponer las armas, bien a refugiarse en Francia. La campaña fue secundada con celo por la población catalana formada en Somatén a partir del 18 de noviembre.

\section{LA POMPA DEL PRETENDIENTE}

La influencia de la incipiente fotografia se aprecia en ciertas estampas estáticas, de estilo no obstante propagandístico. «El fotógrafo retratista -escribió Ernest Lacan- se convierte en el intermediario indispensable entre las grandes figuras de la Historia y la posteridad, que querrá conocer sus rasgos físicos en la misma medida en que conocerá sus nombres" ${ }^{33}$. Ante "Don Carlos au milieu de ses partisans", 8 de junio de 1872 (Fig. 24) cabe la frase de Silvio Lago sobre las escenas parisi-

33 Lopez MOndejar, Publio, Las Fuentes de la Memoria. Fotografia y Sociedad en la España del siglo xix. Madrid. Lunwerg Ministerio de Cultura, 1989, pág. 48. 


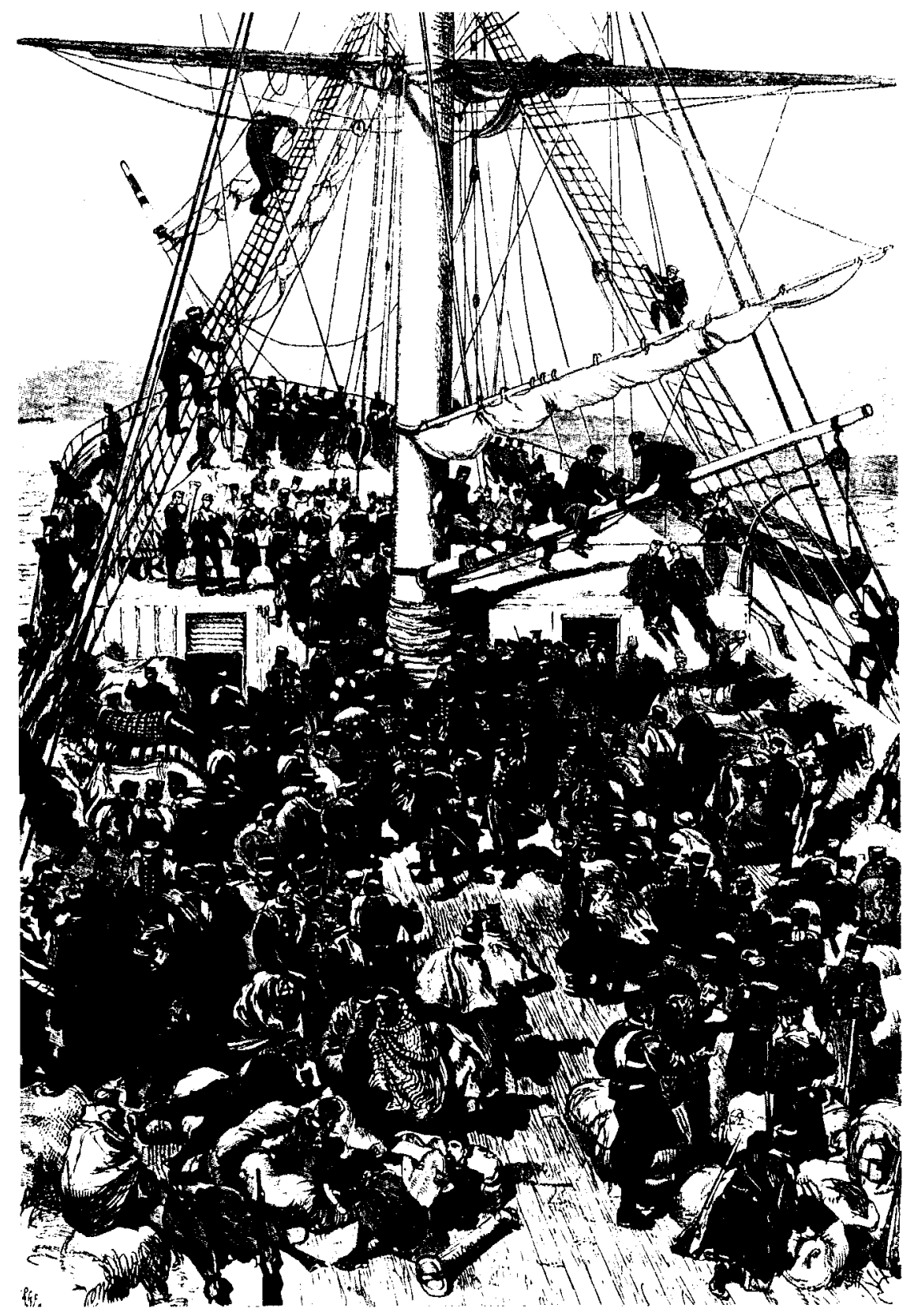

Fig. 22. Le Monde Illustré, diciembre 12, 1874. 
La campaña carlista (1872-1876) en Le Monde Illustré: los dibujos ...

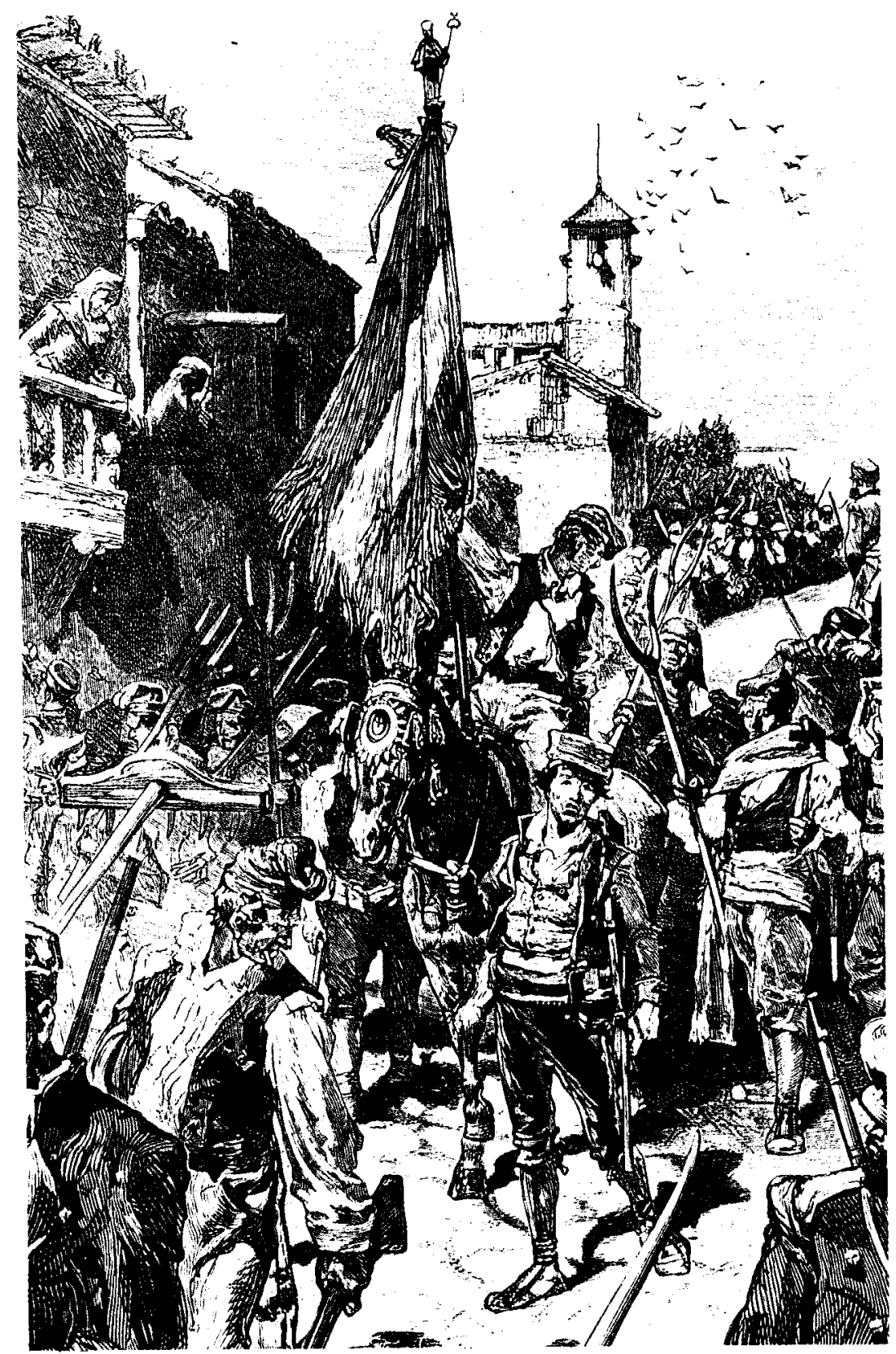

Fig. 23. Le Monde Illustré, diciembre 18, 1875. 


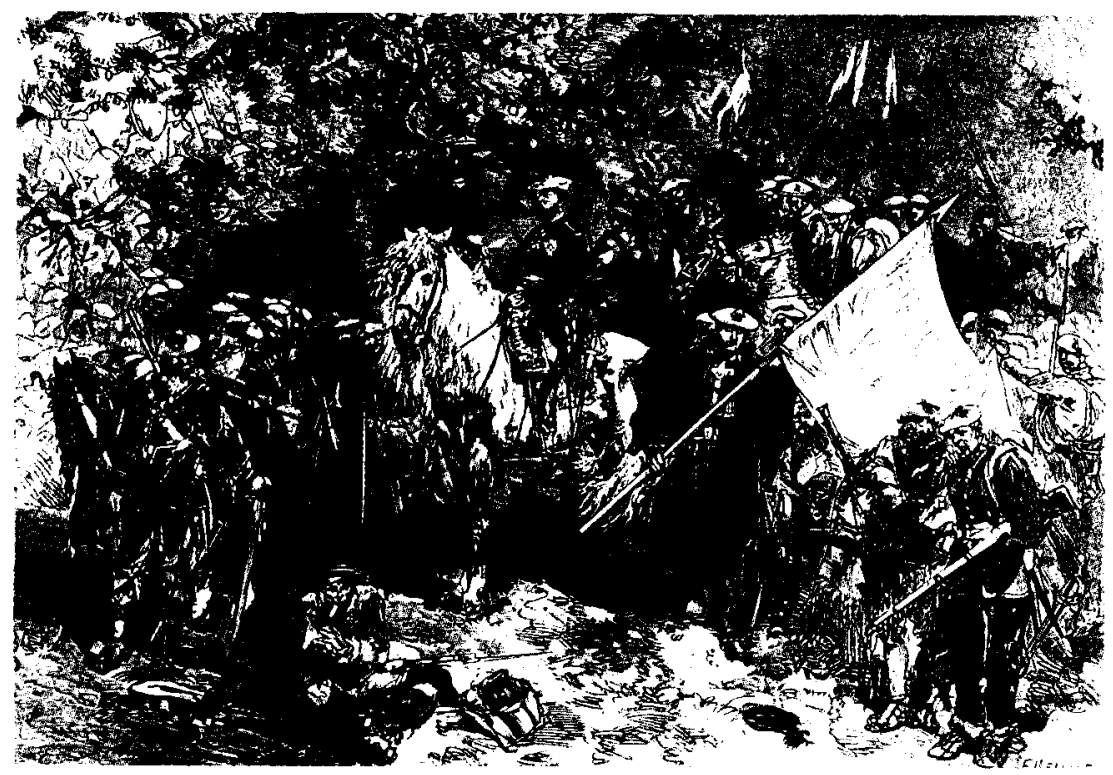

Fig. 24. Le Monde Illustré, junio 8, 1872.

nas de Vierge: "No solamente no se echa de menos la fotografía, sino que la superan en belleza y hasta en exactitud" ${ }^{34}$. Una linea fina muy reiterada, recrea formas y volúmenes muy complejos, envueltos en las sombras de la escena nocturna. El follaje, por encima y a la izquierda de Don Carlos, parece tener la textura de un óleo. La factura preciosista de Fortuny, que triunfaba en Italia y en Francia en esos años, se deja ver en los detalles con que cuida a los personajes y en la minuciosidad de vestiduras y ornamentos (placa de Don Carlos, cruz blanca del soldado, las crines del caballo blanco rodeadas de oscuridad). Por el contrario, la masa de soldados abocetados al fondo, a izquierda y derecha, nos recuerda el trazo ágil y fresco de la pintura impresionista, en aquellos momentos alcanzando su auge. La imagen de la guerra es un contraste entre la prepotencia, el orgullo de Carlos VII, serio, sentado en su caballo blanco y protegido por sus soldados, y el esperpéntico «bufón» en primer plano a los pies, liando un cigarrillo, un célebre espía al servicio de don Carlos, conocido por el sobrenombre de «Lince». A la derecha, el proto-

34 LAGO, Silvio, "Artistas de ayer, Urrabieta Vierge», La Esfera, agosto 17, 1929. 
tipo de voluntario de la Causa, un cura llevando la bandera, cruzado de Dios, Patria y Rey.

Como Meissonier, a quien no conocia, Vierge gusta de documentar meticulosamente la escena militar («Bataille de Somorrostro. Prisonniers espagnols amenés devant don Carlos, pendant l'action", 21 de marzo de 1874) (Fig. 25) detallando rasgos tanto de la fisonomia de los soldados como de los uniformes. En la Exposición de 1889 que presidía Meissonier, éste propuso a Daniel (entonces victorioso de su hemiplejía, pero con dificultades en el habla) para medalla de oro y para la concesión por

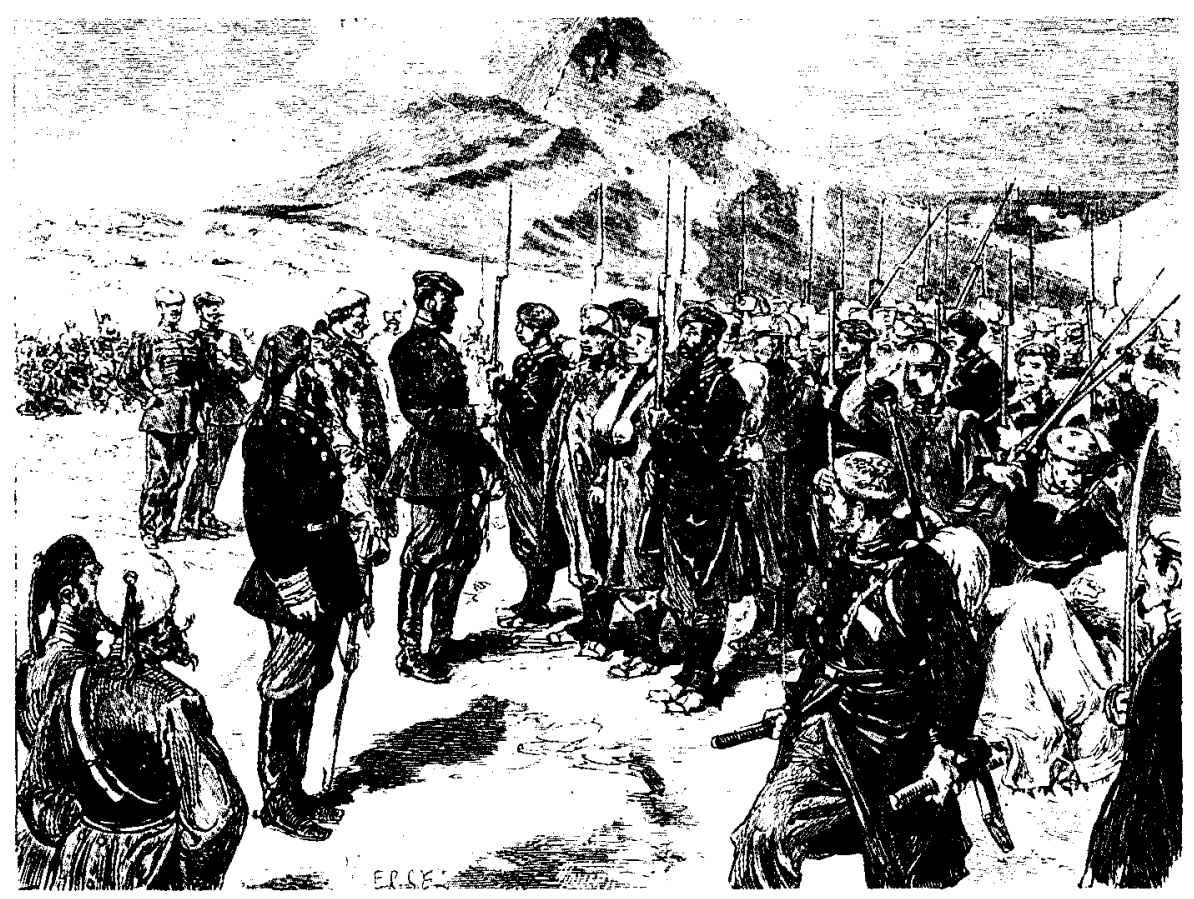

Fig. 25. Le Monde Illustre, marzo 21, 1874. 
el Gobierno de la Legión de Honor ${ }^{35}$. En el grabado los rostros reflejan la emotividad del momento: gravedad, tristeza, valiente ironia. Vierge eterniza el momento con un paisaje lleno de "objetividad geológica" ${ }^{36}$, lo que revela quizás la influencia de Carlos Haes, catedrático de paisaje, desde 1857, en la escuela de San Fernando, a cuya clase habia asistido Vierge. En frase de Dionisio Pérez, "los paisajes de Carlos Haes, dulces, suaves, melancólicos se aparecen a sus ojos como magnificos escenarios donde colocar las figuras de Madrazo (de quien vierge fue alumno) tan pulcras, tan acabadas" ${ }^{37}$. Las batallas de Somorrostro fueron el más significativo acontecimiento militar en el empeño de los carlistas por la toma de Bilbao. A mediados de febrero habia comenzado el sitio de "la invicta villa", nombre que aquéllos ansiaban borrar. Los campos de Somorrostro van a ser testigos de encarnizadas luchas entre ambos bandos. "Se acabó la época de las escaramuzas calificadas por los carlistas con el pomposo término de batalla; en Somorrostro quedan miles y miles de cadáveres" ${ }^{38}$.

La guerra terminaba. El general Primo de Rivera entra triunfalmente en la ciudad santa del carlismo, Estella, el 19 de febrero de 1876, y el 28 don Carlos cruza la frontera francesa por Arnegui, cerca de Valcarlos, seguido por los batallones castellanos, y por muchos jefes y oficiales de los batallones vascos-navarros: "Evènements d'Espagne.- Arrivée de Don Carlos au Pont d'Arneguy, frontiére française", 11 de marzo de 1876 (Fig. 26). Le Monde I/lustré es la única revista que capta este momento. La guardia francesa, con los sables desenvainados y a caballo, Don Carlos delante casi solo, y los soldados carlistas rompiendo sus armas, humillados, en los mojones de la frontera, donde aquél pronuncia la histórica palabra «iVolveré!». Es la extraordinaria factura de Vierge la que confiere un especial valor estético a la escena. Aunque el porte de Don Carlos no es ya el de las estampas anteriores, su guardia real mantiene una altivez de élite "Bien que très-fatiguées, ces troupes sont remarquables par leur belle tenue, principalement l'état-major et la cavalerie de la garde de don Carlos; ce regiment, qui porte le spencer et le pantalon de nos chasseurs d'Afrique, est coiffé d'un béret rouge avec une petite plaque en cuivre portant les initiales D. C.".

35 Pérez. Dionisio, obra citada, pág. 28.

${ }^{36}$ Gaya Nuno, Juan Antonio, Arte del siglo XIX, Ars Hispaniae, Vol. XIX, Madrid, Editorial Plus-Ultra, 1966. pág. 369.

${ }_{37}$ Perez, Dionisio, obra citada, pág. 11.

3 Garmendia, Vicente, La Segunda Guerra Carlista (1872-1876). Madrid. Siglo xix Editores, 1976, pág. 25. 


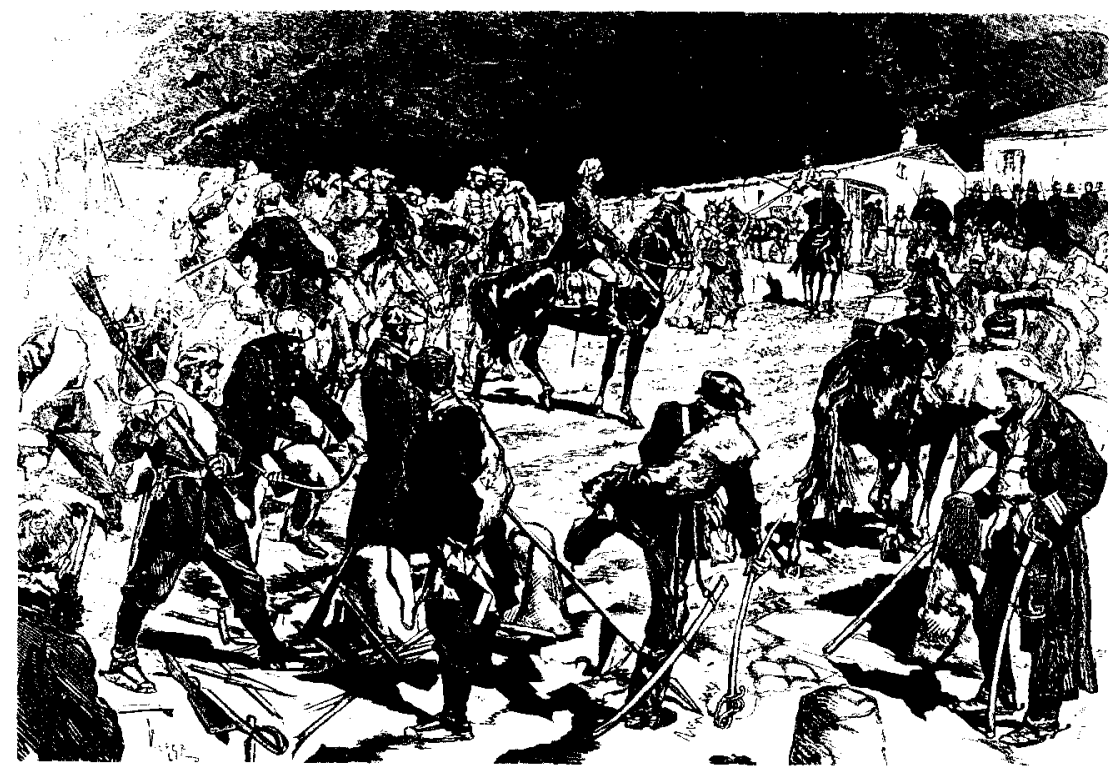

Fig. 26. Le Monde I/lustre, marzo 11, 1876.

Como señaló Charles Iriarte, cronista primero y director luego de $L e$ Monde Illustré, en un tributo a Vierge del año $1889^{39}$, "le mouvement et le fureur dans les combats, la gaîté et l'animation dans les fêtes, la pompe et l'éclat dans les grandes cérémonies, en un mot toujours et partout la vie ..." ${ }^{40}$ resumen el triunfo de este artista de dos patrias, dibujante con una y otra mano, en la transición de la xilografía al fotograbado, Daniel Urrabieta Vierge, nacido en Madrid el 5 de marzo de 1851, muerto en Boulogne sur Seine el 10 de mayo de 1904.

39 M. A., “Daniel Urrabieta Vierge», La llustración Artística, Núm. 424, Febrero 1890 , pág. 482.

40 Marthold, Jules DE, obra citada, pág. 113. 
